2019-09

Flexural performance and cost efficiency of carbon/basalt/glass hybrid FRP composite laminates

Chen, D

http://hdl.handle.net/10026.1/14734

10.1016/j.tws.2019.03.056

Thin-Walled Structures

Elsevier

All content in PEARL is protected by copyright law. Author manuscripts are made available in accordance with publisher policies. Please cite only the published version using the details provided on the item record or document. In the absence of an open licence (e.g. Creative Commons), permissions for further reuse of content should be sought from the publisher or author. 


\title{
Flexural performance and cost efficiency of carbon/basalt/glass hybrid
}

\section{FRP composite laminates}

\author{
Dongdong Chen ${ }^{1}$, Guangyong Sun ${ }^{1,2,}$, Maozhou Meng ${ }^{3}$, Zhi Xiao ${ }^{1}$, Qing Li $^{2}$ \\ ${ }^{1}$ State Key Laboratory of Advanced Design and Manufacture for Vehicle Body, \\ Hunan University, Changsha, 410082, China \\ ${ }^{2}$ School of Aerospace, Mechanical and Mechatronic Engineering, The University of \\ Sydney, Sydney, NSW 2006, Australia \\ ${ }^{3}$ School of Engineering, Plymouth University, Plymouth, United Kingdom
}

\begin{abstract}
This study investigates the interply hybridization of carbon fibre reinforced polymer (CFRP) composite laminate to improve the flexural performance and cost efficiency. Carbon layers were replaced partially by basalt and/or glass fibres to explore the effects of hybrid ratio and stacking sequence on the flexural behaviour and material usage. Hybrid laminates were manufactured by vacuum assisted resin transfer molding (VARTM) process. Three-point bending tests were carried out to characterize the flexural properties and failure mechanisms of the hybrid composite laminates. The fracture surfaces were examined by scanning electron microscopy (SEM). The results showed that flexural strength and modulus of the hybrid laminates decreased with the increase in the hybrid ratio of basalt fibres ranging from 0 to $50 \%$; however negligible effects on flexural properties were observed when hybrid ratio increased further up to $75 \%$. A higher flexural modulus can be obtained by placing carbon layers at both tensile and compressive sides symmetrically, and a higher flexural strength can be achieved by placing basalt or glass fibre through a sandwich-like stacking sequence with a hybrid ratio of $50 \%$. The finite element modelling and classic laminate theory (CLT) analysis were also conducted through validation against the experimental results, which enabled to reveal the details of strain, damage and fracture subject to bending. The study showed a better material efficiency for glass/carbon hybrid laminates in terms of strength/cost and modulus/cost ratio; and the benefit of such cost efficiency of hybridization were discussed for potential applications.
\end{abstract}

Keywords: Carbon fibre, basalt fibre, glass fibre, hybrid, flexural, classic laminate theory,

\footnotetext{
* Corresponding Author: Tel: +86-13786196408; Email: guangyong.sun@sydney.edu.au.
} 
cohesive zone theory, finite element analysis 


\section{Introduction}

Lightweight design is becoming more and more important, particularly in train, wind energy and automotive industry, in which fibre reinforced polymer (FRP) composites have been widely used thanks to its excellent strength to weight ratio, good fatigue resistance and elevated chemical stability compared to traditional engineering materials[1-3]. Carbon fibre reinforced polymer (CFRP) composites exhibit irreplaceability in a range of engineering structures such as ships, sport equipment and aircraft, which have particularly higher lightweight requirements [4-7]. However, its material and manufacturing cost largely restricts its applications in traditional engineering field such as automobile industry $[8,9]$. In the meantime, CFRP composites are susceptible to stress concentration due to the inherent brittleness. Even minor accidental impact or static overload could potentially cause the severe damage to the structure, such as matrix cracking or delamination, sacrificing load carrying capacity. Often, catastrophic failure can take place without sufficient warning due to the poor residual strength [10].

A variety of strategies have been proposed to improve the brittleness of CFRP over decades. One of the prevalent ways is to toughen the polymer matrix by adding nano-scale reinforcement or to replace the thermosetting matrix with thermoplastics[11]. It has been shown that the mechanical properties and multi-functionality of matrix can be improved by adding a small amount of carbon nanotubes (i.e. $0.5 \mathrm{wt} \%$ ) [12, 13]. Thermoplastic matrices exhibit appealing advantages to composite materials, including more environmental friendly properties and recycling efficiencies $[14,15]$. Compared to traditional thermoset resins, thermoplastic matrix has been investigated and proven to be effective for improving resistance to impact damage [16].

Hybridization with some high elongation fibres is an alternative way to improve the performance of CFRP composites [11]. In this fashion, the advantages of carbon fibres can be maintained whereas the disadvantages can be alleviated, and the material cost of carbon fibres can be reduced by introducing low cost fibres. The toughness of composite can be improved when the brittle carbon fibres are partially replaced by ductile fibres such as glass/basalt fibres $[9,17]$. In practice, fracture of brittle fibres in the hybrid composites can be used for health monitoring purpose [18] or as a warning sign prior to final catastrophic failure [19]. From material perspective, hybrid structural configurations can be categorized in three scales, namely layer-by-layer, yarn-by-yarn and fibre-by-fibre [11]. The layer-by-layer technique has exhibited its advantages on relatively lower cost of material by replacing high cost carbon fibre with other lower ones.

Glass fibre has been considered to be an applicable hybrid material candidate due to its 
higher strain-to-failure quotient over the carbon fibre for unidirectional/woven composites [10, 17, 19-22], exhibiting enhanced strength and modulus of hybrid composite through a proper stacking configuration of carbon and glass layers. Flexural properties of bidirectional hybrid epoxy composites reinforced by E-glass and T700S carbon fibres with an inter-ply configuration has been studied in [20], which showed the advantage of balancing 2-D flexural properties for various loading directions. Kalantari et al. [21] conducted an optimal analysis for unidirectional composite laminate hybrid with S-glass and T700S carbon fibre under flexural loading; and interestingly, they found that the optimal configurations was not always in the critical hybrid ratio with the maximum flexural strength or hybrid effect.

To further understand flexural behavior of laminated composites, substantial numerical studies have been conducted in literature. For example, Meng et al. [23] investigated the effects of carbon fibre layup on fracture initiation in laminated composites using three-dimension (3D) finite element (FE) analysis and classic laminate theory (CLT), by simulating damage initiation under bending. Ullah et al. [24, 25] introduced a cohesive zone element in two-dimensional (2D) FE model for predicting the delamination behavior of carbon/glass FRP composite under large-deflection bending, showing the capability of modelling damage initiation and propagation. Jalalvand et al $[26,27]$ also used the cohesive elements at the interface of carbon/glass fibre to model the delamination in the hybrid laminates with different layup in tension. Dong and co-workers $[28,29]$ studied the effects of flexural modulus, flexural strength and stress distribution of carbon/glass hybrid laminates in their FE analyses. Note that there exist fairly complex failure mechanisms in the flexural loading process of hybrid laminates that involves fibre fracture on the compressive side, matrix crack and delamination etc. The effects of hybridization on flexural failure mechanism have remained demanding and under-studied in literature to date.

Basalt fibre has been classified to be the material for military applications traditionally and has been extensively used since its discovery [30]. Due to its redundant resource and unique manufacturing process, basalt fibre is cheaper and more environment-friendly than glass/carbon fibres [31]. Due to the low price and intermediate mechanical properties, one of the potential applications of basalt fibre is to combine with other composite materials for lightweight structures, enabling to reduce usage of CFRP while maintaining the high mechanical properties. In several recent studies [9, 32-34], basalt fibre has been introduced as a substitute of glass fibre to mix with carbon fibre. In this regard, the study was conducted on tensile fatigue behavior of various fibre reinforced polymer composites, such as carbon, glass, polyparaphenylenl benzobisoxazole (PBO), basalt fibre as well as the hybrid laminates with carbon/glass and carbon/basalt fibres [35]. It was found that the fatigue resistance was improved by using hybrid basalt/carbon fibres in comparison with net basalt fibre. The effect 
of stacking sequences of carbon and basalt fabrics on flexural properties was explored in [9], which showed that higher flexural strength and modulus were achieved by placing carbon fibre on the compressive side. Transverse impact characteristics of carbon/basalt fibres hybrid laminates were reported in $[32,34]$, which demonstrated that the impact performance increased with increasing hybrid ratio, while flexural modulus depended on their composition. A series of experimental tests including tensile, flexural, interlaminar shear and weight drop impact, were conducted for laminate hybrid laminates with carbon, basalt and flax fibres [33].

The above literature studies on flexural behavior of laminate hybrid with carbon/basalt fibres were mainly for woven fabrics; where little attention has been devoted to unidirectional fibre. Further, it is noted that one purpose of using a hybrid composite configuration is to lower the materials cost, however the existing studies on hybridization are concentrated on the mechanical properties without specifically taking into account this criterion.

This study aimed to explore both the flexural properties and cost efficiency of interply hybrid carbon/glass/basalt composite laminates. The effects of hybrid ratio, stacking sequence and fibre combination on flexural properties were systematically investigated. In this paper, the classic laminate theory (CLT) was adopted to predict the flexural modulus of hybrid laminate. Scanning electron microscopy (SEM) was utilized to analyse the fracture surface. Finite element (FE) model was developed to simulate the damage onset and progression in each layer of hybrid laminate under transverse loading.

\section{Materials and Methods}

\subsection{Materials}

The layer by layer mixtures of three types of fibres were reinforced by the same epoxy resin in this study. Carbon fibre (T700-12K, unidirectional, surface density $235 \mathrm{~g} / \mathrm{m}^{2}$ ) and glass fibre (600 tex, unidirectional, surface density $202 \mathrm{~g} / \mathrm{m}^{2}$ ) were supplied by Weihai Guangwei Composites Co., Ltd, while the basalt fibre (600 tex, unidirectional, surface density $300 \mathrm{~g} / \mathrm{m}^{2}$ ) was supplied by Sichuan Aerospace Tuoxin Basalt Industrial Co., Ltd. The resin matrix was a blend of epolam 5015(resin)/ epolam 5014(hardener), provided by Sino Composite Co., Ltd.

\subsection{Sample preparation}

Square hybrid composite plates were fabricated by vacuum-assisted resin transfer molding (VARTM) process shown in Fig. 1. The unidirectional fabrics were cut into pieces with a dimension of $330 \mathrm{~mm} \times 330 \mathrm{~mm}$ first, and then were placed on the plate mold with 8 plies with proper stacking sequences shown in Fig. 2. The epoxy resin was degassed before 
being mixed with the hardener in an epoxy/hardener ratio of $3: 1$, and then the mixture was injected into the fabrics through the resin inlet position after sealing the mold. A pressure of $-0.1 \mathrm{MPa}$ created by the vacuum pump was maintained through impregnation and curing process for 24 hours at a constant temperature about $28^{\circ} \mathrm{C}$.

(a)

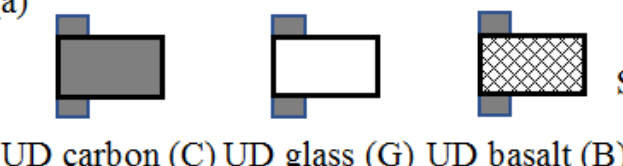

(b)

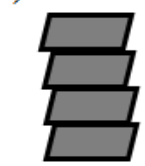

C laminate

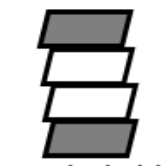

CG hybrid

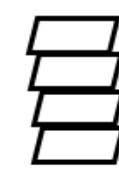

G laminate

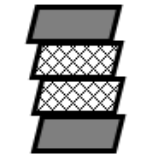

CB hybrid (c) Vacuum bag Distribution mesh Peel ply

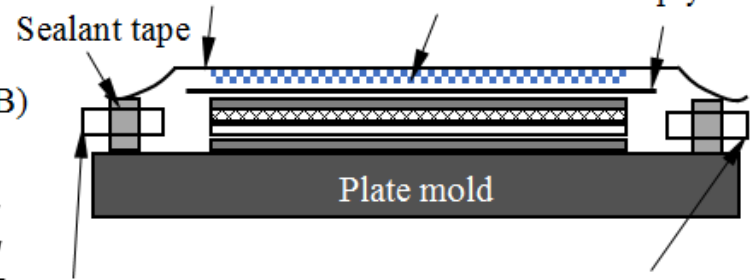

Resin outlet

Fig. 1. Schematic of the VARTM process. (a) unidirectional weaves; (b) fabric to pieces, layup; (c) vacuum bagging.
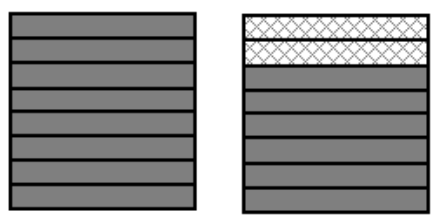

CFRP

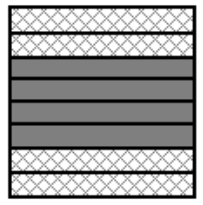

$\mathrm{B} 2 \mathrm{C} 4 \mathrm{~B} 2$

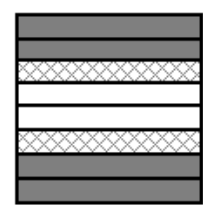

\section{C2BG2BC2 BGC4GB}

C2B4C2

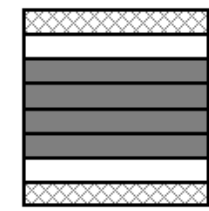

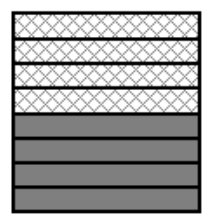

B4C4

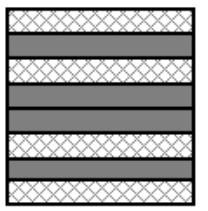

$\mathrm{BCBC} 2 \mathrm{BCB}$

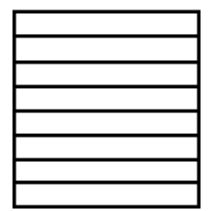

GFRP

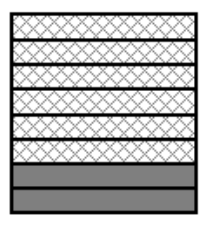

B6C2

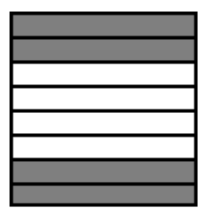

$\mathrm{C} 2 \mathrm{G} 4 \mathrm{C} 2$

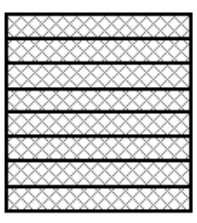

BFRP

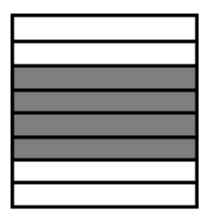

\section{G2C4G2}

$\square$ Carbon fibre layer

Basalt fibre layer

$\square$ Glass fibre layer

Fig. 2. Laminate codes of stacking sequences.

Three hybrid factors were considered here as shown in Fig. 2, i.e. hybrid ratio, hybrid stacking sequence and fibre type. Hybrid ratio $\left(r_{f}\right)$ was defined based on the volume ratio of substitutive fibre (glass or basalt) to the carbon fibre. For example, ' $r_{f}=0$ ' indicates pure 
carbon fibre fabric, while ' 1.0 ' indicates completed replacement of carbon fibre by either glass or basalt fibre.

Effects of layup sequence were analyzed using several commonly-used composite structures (sandwich-like types shown in Fig. 2) with the various proportion of carbon fibre content. All the hybrid laminates were constructed with 8 plies to achieve the consistent laminate thickness. Fibre weight fraction was measured as around $68 \%$ after curing.

\subsection{Flexural testing}

The rectangular samples with a dimension of $90 \times 15 \mathrm{~mm}$ were cut from the composite plates fabricated by VARTM technology mentioned above. The flexural test with a span-to-thickness ratio of 32 was performed at a constant speed of $5 \mathrm{~mm} / \mathrm{min}$ at room temperature according to ASTM D7264. At least three repeats were conducted for each laminate configuration. As reported in [11] that hybrid fibre plies showed a strong effect on mechanical properties and failure mechanisms. Three variables are considered to evaluate such hybrid effect according to the following equations [36]:

$$
\begin{aligned}
& \sigma=\frac{3 P L}{2 w h^{2}} \\
& E=\frac{L^{3} m}{4 w h^{3}} \\
& \varepsilon=\frac{6 \delta h}{L^{2}}
\end{aligned}
$$

where $\sigma, \delta$ and $\varepsilon$ represent the maximum flexural stress (flexural strength), mid-span deflection and maximum strain at the outer surface of the mid-span, respectively. The flexural secant modulus of elasticity $(E)$ is also presented here. $P, L, w, h$ and $m$ are maximum flexural load, support span, width of specimen, thickness of the specimen and slope of the secant of the initial force-deflection curve.

\subsection{Characterization and analysis}

\subsubsection{Classical lamination theory (CLT)}

The flexural modulus and stress distribution across each hybrid laminate were calculated using classical lamination theory as reported in [23, 28, 29]. Fig. 3 shows the neutral mid-plane of the laminate which contains the coordinate system and detailed loading information. As illustrated in Fig. 3, a global $x-y-z$ coordinate system was defined based upon the $x-y$ plane located within the lamination plane, and $z$ axis across the thickness direction. The mid-plane is located at the half thickness of the hybrid laminate $(z=0)$. The fibre angle of each ply was arranged to be zero along the $x$ direction. 
A 3D CLT formula was used to estimate the stress components here. Assuming that the symmetric $y z$-plane remains the same and is normal to the $x$-axis before and after bending tests [37], the strain distributes in the $z$ direction is given by:

$\varepsilon=\varepsilon_{0}+Z \kappa$

where $\varepsilon_{0}$ is the strain vector and $\kappa$ is the curvature of the mid-plane. For a specimen subjected to three-point bending with a symmetric ply sequence, the constitutive equations can be simplified in Eq. (5).

$\left\{\begin{array}{l}0 \\ M\end{array}\right\}=\left[\begin{array}{ll}A & B \\ B & D\end{array}\right] \bullet\left\{\begin{array}{c}\varepsilon_{0} \\ \kappa\end{array}\right\}$
$[A]=\sum_{k=1}^{N}\left(\bar{Q}_{i j}\right)_{k}\left(z_{k}-z_{k-1}\right)$
$[B]=\frac{1}{2} \sum_{k=1}^{N}\left(\bar{Q}_{i j}\right)_{k}\left(z_{k}^{2}-z_{k-1}^{2}\right)$
$[D]=\frac{1}{3} \sum_{k=1}^{N}\left(\bar{Q}_{i j}\right)_{k}\left(z_{k}^{3}-z_{k-1}^{3}\right)$

where the bending moment vector is $M=\left[\begin{array}{lll}M_{X X} & 0 & 0\end{array}\right]^{T}$ as shown in Fig. 3. Strains $\varepsilon_{0}$ and curvature $\kappa$ at the mid-plane can be calculated by the external load $P . \bar{Q}$ is the stiffness matrix of each ply varies with material type that can be evaluated from the compliance matrix $S \quad[23]$ given in Eq. (9).

$S=\left[\begin{array}{cccccc}1 / E_{1} & -v_{12} / E_{1} & -v_{12} / E_{1} & 0 & 0 & 0 \\ -v_{12} / E_{1} & 1 / E_{2} & -v_{23} / E_{2} & 0 & 0 & 0 \\ -v_{12} / E_{1} & -v_{23} / E_{2} & 1 / E_{2} & 0 & 0 & 0 \\ 0 & 0 & 0 & 1 / G_{23} & 0 & 0 \\ 0 & 0 & 0 & 0 & 1 / G_{12} & 0 \\ 0 & 0 & 0 & 0 & 0 & 1 / G_{12}\end{array}\right]$

where $E_{1}, E_{2}$ represent the longitudinal and transverse elastic modulus; $v_{12}$ and $v_{23}$ are the in-plane and transverse Poisson's ratios. $G_{12}$ and $G_{23}$ are in-plane and transverse shear moduli

With the 3D CLT formulas, the flexural modulus of laminate can be calculated according to Eq. (10) [37]. For a symmetric laminate, the strain $\varepsilon_{x}^{z}$ and longitudinal stress $\sigma_{1}^{z}$ are 
given as [23].

$E_{C L T}=\frac{12}{h^{3} d_{11}}$

$\varepsilon_{X}^{Z}=\frac{z P L d_{11}}{4 W}$

$\sigma_{1}^{Z}=E_{k} \frac{Z P L d_{11}}{4 W}$

$d_{11}$ is the first element of the inverse matrix of $[D]$ and $E_{k}$ is the elastic modulus of the $k$-th ply (the same to that of $E_{1}$ as defined in Table 1). With the properties given in Table 1 that followed the in-house material tests as per the ASTM standards [38, 39], the flexural properties of hybrid laminates can be predicted by this 3D classical lamination theory.
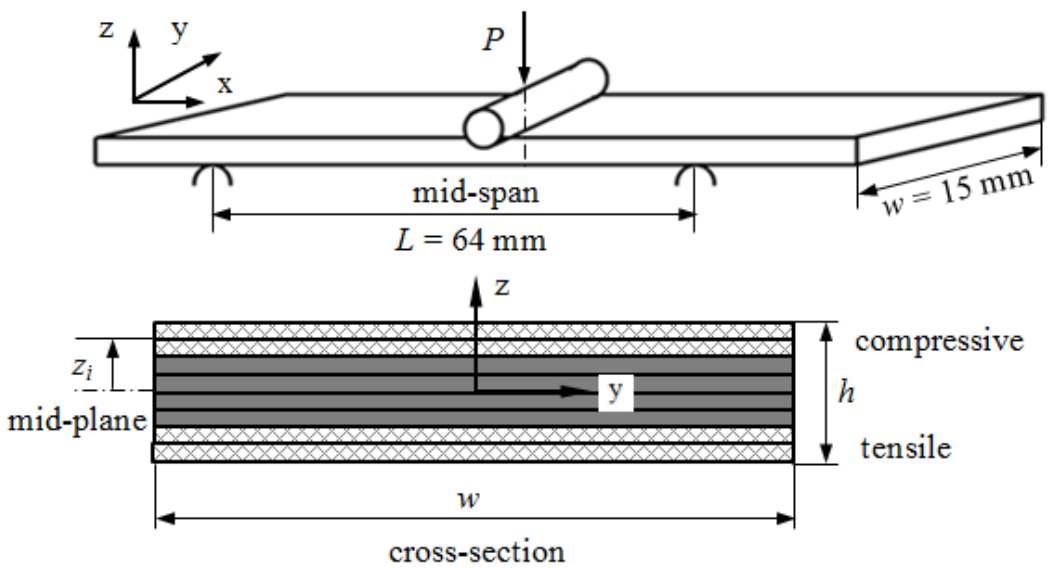

Fig. 3. Schematic profiles of the hybrid composite specimen in the three-point bending setup.

Table 1 Mechanical properties of the carbon/glass/basalt lamina. The compressive modulus and strength are empirically calculated as $90 \%$ and $65 \%$ of their tension according to [40].

\begin{tabular}{llllllllll}
\hline Symbol & $\begin{array}{l}E_{1}^{t} \\
(\mathrm{GPa})\end{array}$ & $\begin{array}{l}E_{1}^{c} \\
(\mathrm{GPa})\end{array}$ & $\begin{array}{c}E_{2} \\
(\mathrm{GPa})\end{array}$ & $v_{12}$ & $v_{23}$ & $\begin{array}{l}G_{12} \\
(\mathrm{GPa})\end{array}$ & $\begin{array}{l}G_{23} \\
(\mathrm{GPa})\end{array}$ & $\begin{array}{c}\sigma_{11}^{t} \\
(\mathrm{MPa})\end{array}$ & $\begin{array}{l}\sigma_{11}^{c} \\
(\mathrm{MPa})\end{array}$ \\
\hline CFRP & 120 & 108 & 8 & 0.21 & 0.42 & 5 & 3 & 2200 & 1430 \\
GFRP & 40 & 32 & 4 & 0.26 & 0.52 & 3 & 3 & 500 & 425 \\
BFRP & 33.1 & 29.8 & 6 & 0.5 & 0.25 & 3 & 3 & 560 & 364 \\
\hline
\end{tabular}

\subsubsection{SEM characterization}

The area close to the fracture position was of particular interest, which was sectioned from the composite laminate for microscopic analysis. The fracture surface along the fibre direction was inspected by a scanning electron microscope (SEM, JSM-IT300LA), which exhibited various failure modes in the hybrid composites. 


\section{Results and Discussion}

\subsection{Comparison of flexural properties}

In this study, carbon fibre was hybridized by basalt fibre and glass fibre, whose elongations are much higher. Although these two fibres are of lower modulus than the carbon fibre, their cost is much lower. The flexural properties of the hybrid laminates were investigated through the 3-point bending tests. Apart from the hybridization of basalt and glass fibres with the carbon fibre, a blend of these three fibre types, had also been analyzed, i.e. BGC4GB and $\mathrm{C} 2 \mathrm{BG} 2 \mathrm{BC} 2$. The average flexural strength, flexural modulus and strain at peak values are shown in Fig. 4.
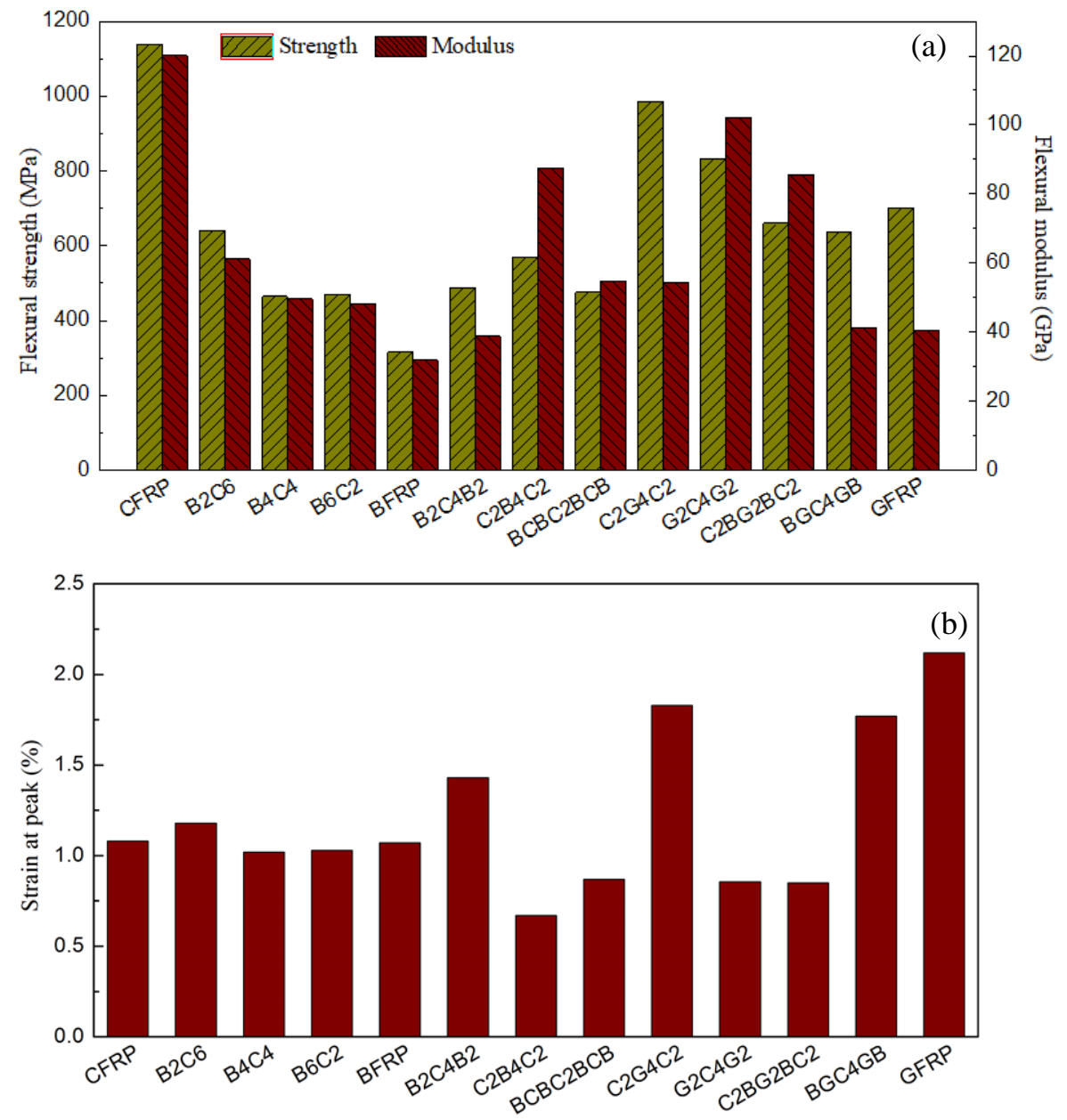

Fig. 4. Comparison of different hybrid configuration: (a) average flexural strength, flexural modulus (b) and strain at peak values.

Effect of hybrid ratio on the apparent flexural modulus/strength was investigated through five different stacking configurations, namely CFRP (0), B2C6 (25\%), B4C4 (50\%), B6C2 (75\%) and BFRP (100\%). It could be observed from Fig. 4(a) that the flexural modulus and 
strength shows a decreasing trend with increase of the hybrid ratio. In contrast, there is no significant change of peak strain with the different hybrid ratios as shown in Fig. 4(b), indicating that carbon fibre dominated failure mode of these hybrid laminates in bending. Different stacking sequences of carbon fibre laminates hybrid with glass or basalt fibre were compared with the same hybrid ratio of $50 \%$. The test results shown in Fig. 4 for the three representative configurations $(\mathrm{B} 2 \mathrm{C} 4 \mathrm{~B} 2, \mathrm{C} 2 \mathrm{~B} 4 \mathrm{C} 2$ and $\mathrm{BCBC} 2 \mathrm{BCB})$ shows that the stacking sequence mainly affected the flexural modulus and strain at peak, while the flexural strength remained a stable value. As for glass/carbon hybrid laminates, stacking sequence shows a rather opposite effect on flexural properties.

\subsection{Hybrid effect on flexural performance}

\subsubsection{Effects of hybrid ratio}

Complicated stress state existed in the bending failure process for composite laminates. Previous studies [29] indicated that the stress distribution across the thickness direction varies from compression to tension side under bending. The carbon fibre layers on the compression side were replaced by basalt fibre layers at different hybrid ratios $(25 \%, 50 \%, 75 \%$ and 100\%), and the effects of such replacement strategy are illustrated in Fig. 5.

As shown in Fig. 5(a), the contact force increases linearly to the peak until the laminates fractured. CFRP exhibited the highest load while BFRP the lowest of all these samples tested. It is noteworthy that BFRP showed a gradual decrease of contact load after peak point, indicating a different failure mode to brittle failure of the CFRP laminate. Flexural force-displacement curves of these composite laminates with different hybrid ratios fell in between those of BFRP and CFRP. It can be clearly observed that the hybrid configuration increased the structural ductility but reduced the flexural strength and modulus compared to CFRP laminate.

The flexural modulus of the hybrid laminates was predicted by 3D CLT, and the comparison between the CLT prediction and experiments is shown in Fig. 5(d). Flexural strength and modulus showed drastic drop by $43 \%$ and $49.1 \%$, respectively with the increase of hybrid ratio from 0 to $25 \%$, in comparison with the pure CFRP laminate. When the hybrid ratio increased from $25 \%$ to $50 \%$, the flexural strength and modulus decreased further to $59 \%$ and $58.6 \%$ respectively. However, these flexural properties remained relatively stable when the hybrid ratio was beyond 50\%. The $\mathrm{B} 6 \mathrm{C} 2$ laminate (hybrid ratio $=75 \%$ ) appeared to be a better stacking configuration for its relatively low cost (by using more low cost fibre) and ductile behavior after peak load. As shown in Fig. 5(b), the maximum strain showed a relatively small fluctuation, with a maximum range of variation about $13 \%$.

The stress $\left(\sigma_{11}\right)$ distributions across the thickness (in $z$ direction) under the load of $150 \mathrm{~N}$ 
are showed in Fig. 5(e). A significant stress reduction appeared when the carbon layers were replaced on the compressive side by the basalt layers, due to the lower modulus of basalt layers. Stress state in each lamina was also changed due to the introduction of basalt layer. The jump of stress distribution across the hybrid laminates section mainly appeared in the interface between different materials as observed from Fig. 5(e). It can be found that the B2C6 (hybrid ratio $=25 \%$ ) and BFRP laminates presented the minimum tensile and compressive stresses at outsides among all the specimens separately. With increase in the hybrid ratio, the stress distribution across the laminate increased on the tensile side but decreased on the compressive side. Values of tensile stress for the hybrid laminates on the tensile side increased while flexural strength decreased due to a lower strength of basalt layer. 

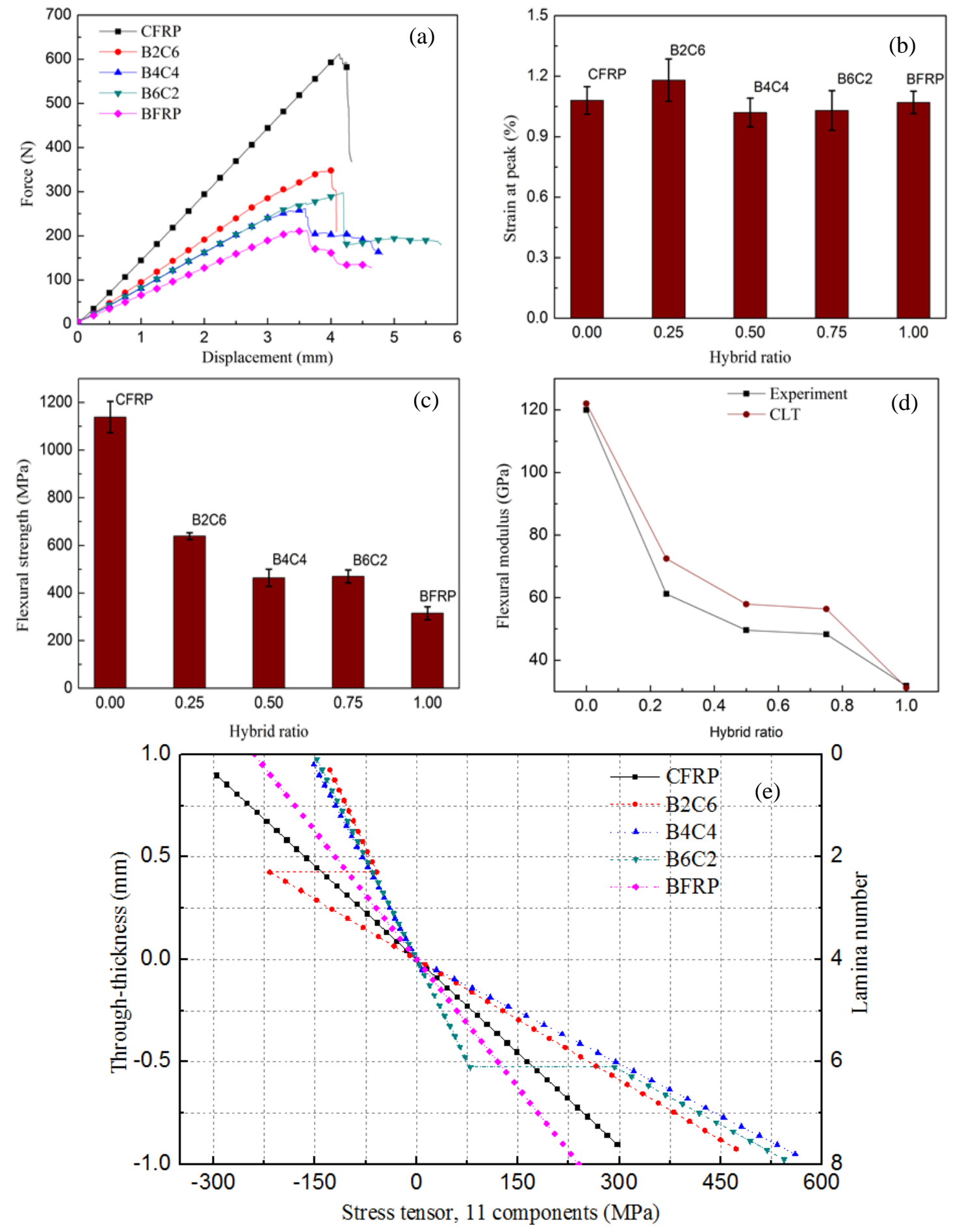

Fig. 5. Effect of hybrid ratio on flexural properties: (a) force-displacement curves, (b) flexural strength, (c) strain at peak, (d) comparison of flexural modulus between the experiment and CLT evaluation, and (e) stress $\left(\sigma_{11}\right)$ distribution across the thickness under the transverse load of $150 \mathrm{~N}$.

\subsubsection{Effects of stacking sequence}

Strong effect of hybrid stacking sequence on the flexural properties was reported in [9, 10]. In our present study, all the composite laminates were unidirectional and have relatively larger gap of the mechanical properties of these two types of fibres, which differs from the 
work in $[9,10]$. In this study, four basalt layers and four carbon layers were utilized with the stacking sequences outlined in the schematic shown in Fig. 2 for the hybrid ratio of $50 \%$.

Inserting basalt layers into carbon layers improved the ductile property of the hybrid laminates but downgraded the flexural modulus and strength, as discussed in section 3.2.1. It can be observed from Fig. 5(a) and Fig. 6(a) that the stacking sequence mainly affected the slope of load-displacement curves before peak. Placing 2 carbon layers on the both top and bottom respectively, and the other 4 basalt layers in the central layers yielded the highest flexural modulus and strength of all the hybrid samples (C2B4C2), which were found to be about $28.2 \%$ and $37.9 \%$ lower in the flexural modulus and strain at peak in comparison with those of CFRP. This is because the top and bottom carbon layers borne higher load under bending. Interestingly, non-linear behavior is observed when the bottom side (tension) carbon fibres were partially replaced by basalt fibres, such as BCBC2BCB and B2C4B2. Similar results can also be also found in [9] when the top and bottom carbon layers were replaced by basalt layers with high elongation. It is noteworthy that B2C4B2 showed the maximum strain to peak load which was even higher than that of pure BFRP or CFRP. When the basalt layers were placed homogeneously on both the tensile and compressive sides, i.e. $\mathrm{BCBC} 2 \mathrm{BCB}$, the strain at peak showed an increasing trend (good ductility) but the flexural strength decreased.

Fig. 6(e) shows the CLT evaluation of stress $\left(\sigma_{11}\right)$ distribution for the symmetric stacking configurations of basalt layers. When the carbon layers near the compressive and tensile sides were replaced by basalt layers (B2C4B2), stress reduction can be observed in the basalt layers. At the meantime, B2C4B2 showed the highest strain at peak for its lower modulus. As for $\mathrm{BCBC} 2 \mathrm{BCB}$, it exhibited a large variation in stress distribution across the laminates and the maximum stress appeared on the second lamina on the both tensile and compressive sides. In contrast, the stress distribution within $\mathrm{C} 2 \mathrm{~B} 4 \mathrm{C} 2$ laminate only showed a small reduction near the central plane, and the load state within carbon layers were almost the same as that of CFRP. This implies that replacing the central carbon layers by basalt layers with lower modulus leads to "small reduction" of flexural properties. 

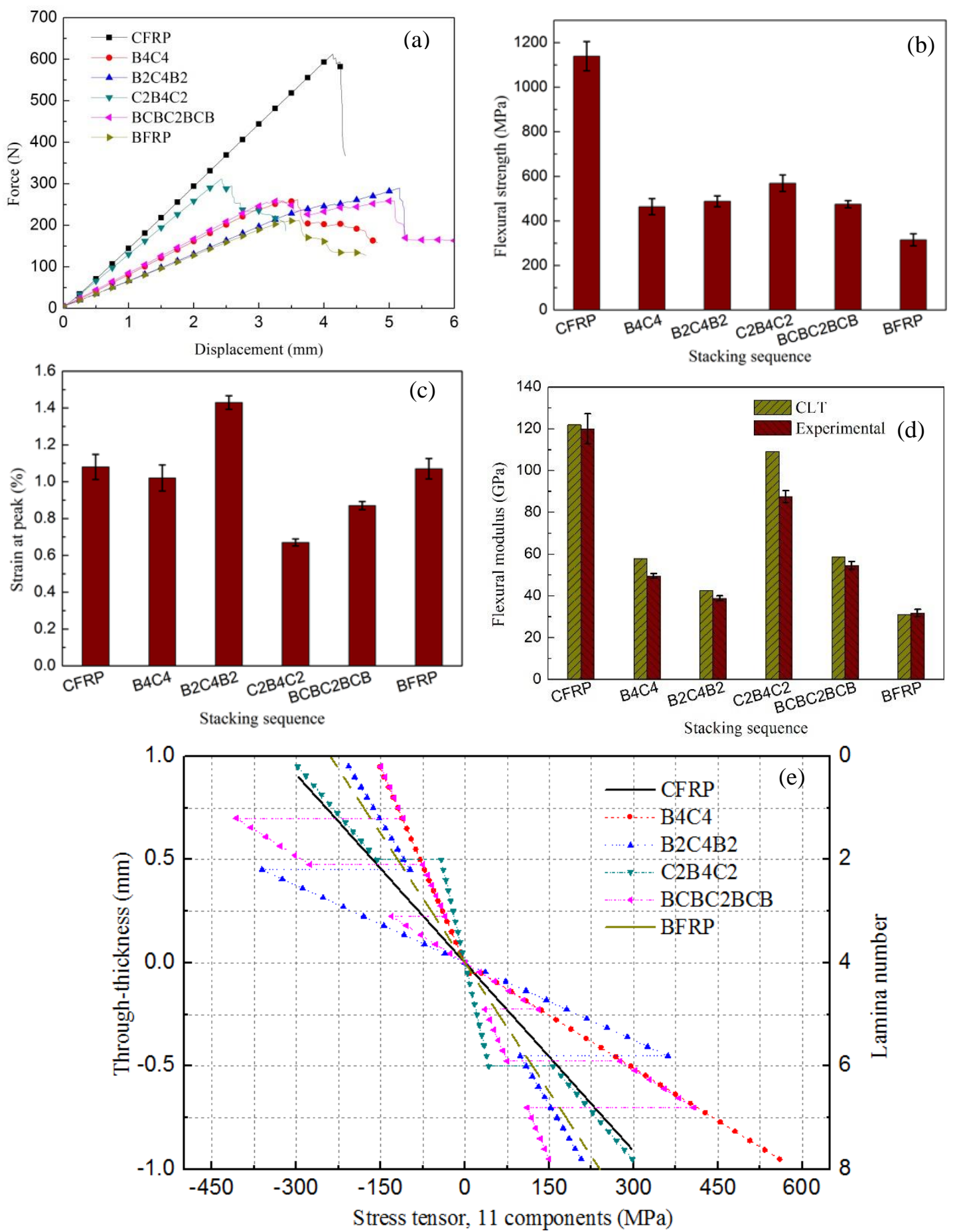

Fig. 6. Comparisons of flexural behavior of hybrid laminates with different stacking sequences with carbon/basalt fibres in terms of (a) force-displacement curves, (b) flexural strength, (c) strain at peak, (d) flexural modulus of experiment and CLT calculation, and (e) stress distribution of $\sigma_{11}$ through the thickness under the load of $150 \mathrm{~N}$.

\subsubsection{Effects of fibre type}

The flexural modulus and flexural strength of glass fibre fall in between basalt and carbon fibres. The hybridization of these three types of fibres (BGC4GB and C2BG2BC2) 
was also prepared for exploring the hybrid effects on their flexural properties. The comparison between the experimental results and CLT estimation is presented in Fig. 7.

As can be seen from Fig. 7, the GFRP laminate had a higher ultimate flexural strain than those of BFRP and CFRP, about $122 \%$ and $27.3 \%$ increase in the ultimate flexural strain relative to that of BFRP. It is interesting to note that the sandwich-like stacking configurations, G2C4G2 and C2G4C2, exhibited very different flexural behavior to those of B2C4B2 and C2B4C2. With such two glass layers located symmetrically on the tensile and compressive sides, G2C4G2 achieved a higher flexural strength (about 15\% higher than that of $\mathrm{C} 2 \mathrm{G} 4 \mathrm{C} 2$ ). It is also found that while the $\mathrm{C} 2 \mathrm{G} 4 \mathrm{C} 2$ laminate presented a higher flexural modulus, the final elongation of $\mathrm{G} 2 \mathrm{C} 4 \mathrm{G} 2$ was much greater due to the higher ductility of glass layers.

The symmetric stacking sequence of hybrid laminates with three types of fibres, $\mathrm{BGC} 4 \mathrm{~GB}$ and $\mathrm{C} 2 \mathrm{BG} 2 \mathrm{BC}$, were chosen for the further analysis. Note that these laminates have the same amount of 4 carbon layers, 2 basalt layers and 2 glass layers respectively. As can be seen from Fig. 7(b) and (d), the flexural strength of these two laminates were almost the same; while the $\mathrm{C} 2 \mathrm{BG} 2 \mathrm{BC} 2$ laminate showed a much higher flexural modulus (about two times of BGC4GB). Compared with G2C4G2, the flexural strength and flexural modulus of BGC4GB showed $35.3 \%$ and $24 \%$ reduction if replacing one glass layer on the tensile and compressive sides with the basalt layers, respectively. On the other hand, the replacement of glass layers by basalt layers near the central plane (e.g. from $\mathrm{C} 2 \mathrm{G} 4 \mathrm{C} 2$ to $\mathrm{C} 2 \mathrm{BG} 2 \mathrm{BC} 2$ ), only about $16.7 \%$ and $20.7 \%$ reduction of flexural modulus and flexural strength can be found from the bending tests.

For the sandwich-like stacking configurations, i.e. G2C4G2 and $\mathrm{C} 2 \mathrm{G} 4 \mathrm{C} 2$, the stress distribution trend was similar to those of $\mathrm{B} 2 \mathrm{C} 4 \mathrm{~B} 2$ and $\mathrm{C} 2 \mathrm{~B} 4 \mathrm{C} 2$. According to Fig. 7(d), $\mathrm{C} 2 \mathrm{G} 4 \mathrm{C} 2$ showed a relatively smaller reduction in the flexural modulus than that of $2 \mathrm{C} 4 \mathrm{G} 2$ compared to CFRP laminate, since stress state near the central plane has less influence on the structural response. With partial substitution of carbon lamina on the tensile/compressive sides, the stress state of glass laminate through the thickness direction showed a more 'efficient' distribution because of its high elongation. Thus more efficient use of carbon/glass layers can be achieved while reducing the number of carbon layers in the laminate. 

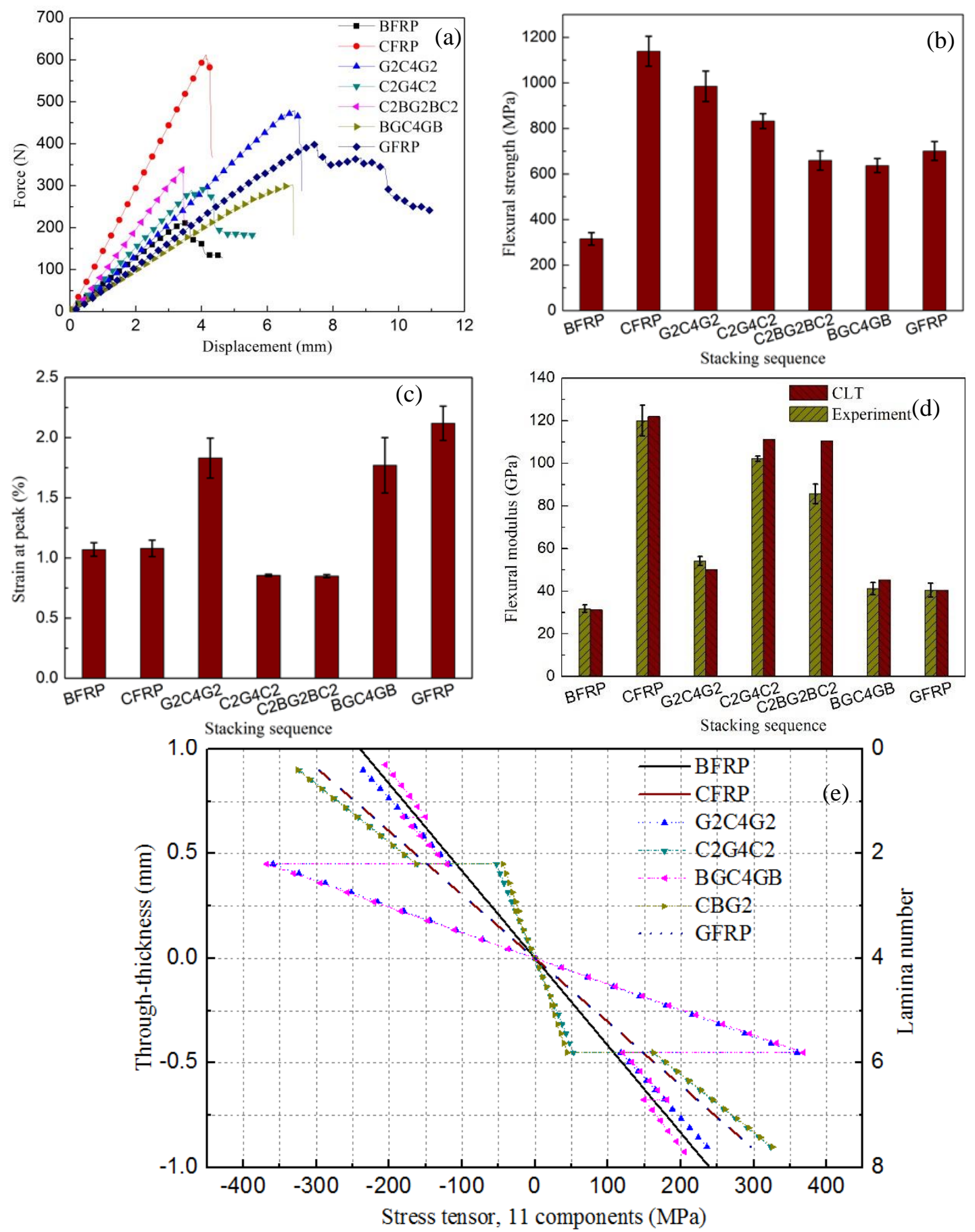

Fig. 7. Comparisons of flexural behavior of hybrid laminates with different fibres in terms of (a) force-displacement curves, (b) flexural strength, (c) strain at peak, (d) flexural modulus of experiment and CLT calculation, and (e) stress distribution of $\sigma_{11}$ through the thickness under the load of $150 \mathrm{~N}$.

\subsection{Failure mechanisms}

The damage distribution of the hybrid laminates was inspected by visible method, and the common failure modes under flexural loading observed include compressive failure, tensile failure, shear and/or delamination [28]. Of these, the compressive failure was the most 
common failure mode in the present cases, which includes fibre kinking, micro-buckling and delamination. According to the hybrid configurations, i.e. fibre type, stacking sequence, hybrid ratio, the compressive failure shifted from surface plies into the central plies [17].

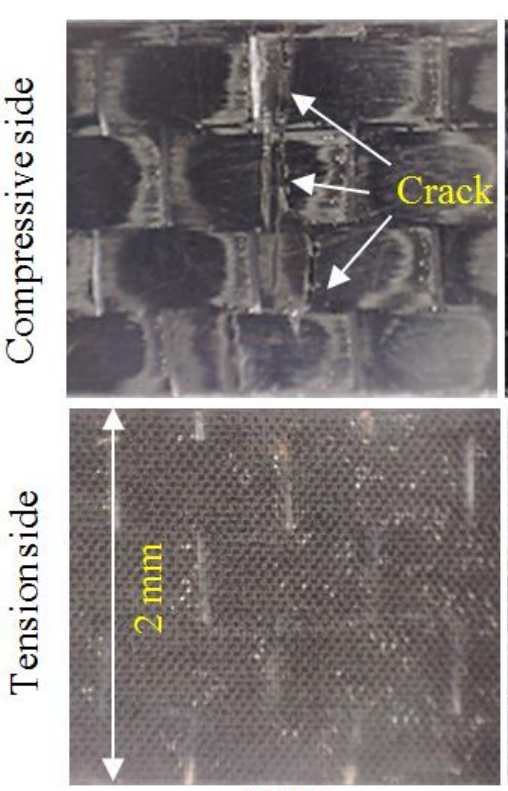

CFRP

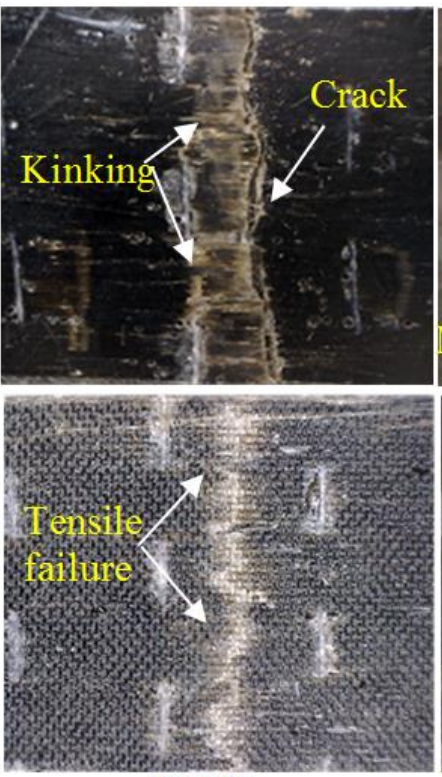

BFRP

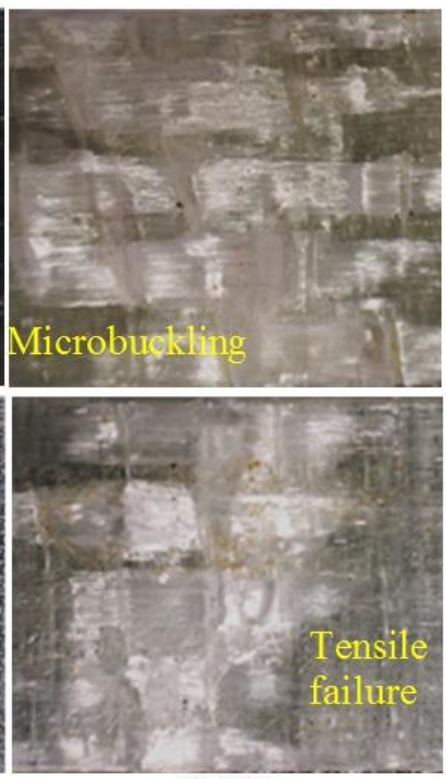

GFRP

Fig. 8. Failure surface of laminates after the flexural testing.

Fig. 8 shows the representative optical images on the top and bottom surface of none hybrid laminates (i.e. CFRP, GFRP and BFRP). A penetrated crack on the compressive side can be seen from the CFRP laminate, but no crack was found on the tension side. This indicates onsite of brittle fracture from the compressive side in bending, leading to a catastrophic failure of the entire laminate. Compared to the CFRP laminate, BFRP and GFRP laminates exhibited both tensile and compressive cracks, exhibiting different failure modes, such as fibre pull-out in the BFRP laminate and micro-buckling in the GFRP laminate. On the compressive side, the BFRP laminate showed a straight crack and kinking band after the fibre fracture, while the GFRP laminate exhibited fibre kinking and micro-buckling. Such a similar failure phenomenon were also reported in [28].

Some typical SEM images of the laminates with the hybrid ratios of 0 and 0.5 are shown in Fig. 9. Onsite of fibre fracture and transverse cracks can be seen first on the compressive side for the CFRP laminate, then propagated across the thickness; finally delamination between the adjacent plies caused ultimate failure, thereby leading to a sudden drop of load carrying capacity. However, no visual kinking band can be found in the CFRP laminate.

The BFRP laminate exhibited somewhat different failure modes compared with the CFRP laminate. Shear failure and fibre fracture appeared first on both the compressive and tensile sides, and followed by crack propagation, leading to complete loss of load carrying 
capacity. Due to combination of ply splitting (delamination) and fibre fracture, the adjacent plies on the compressive side failed, leading to the appearance of kink band. The extension of fracture area was significantly larger than that of CFRP due to a poor fibre/matrix interface and a larger diameter of fibre yarn (13 $\mu \mathrm{m}$ for BFRP and $6.8 \mu \mathrm{m}$ for CFRP).
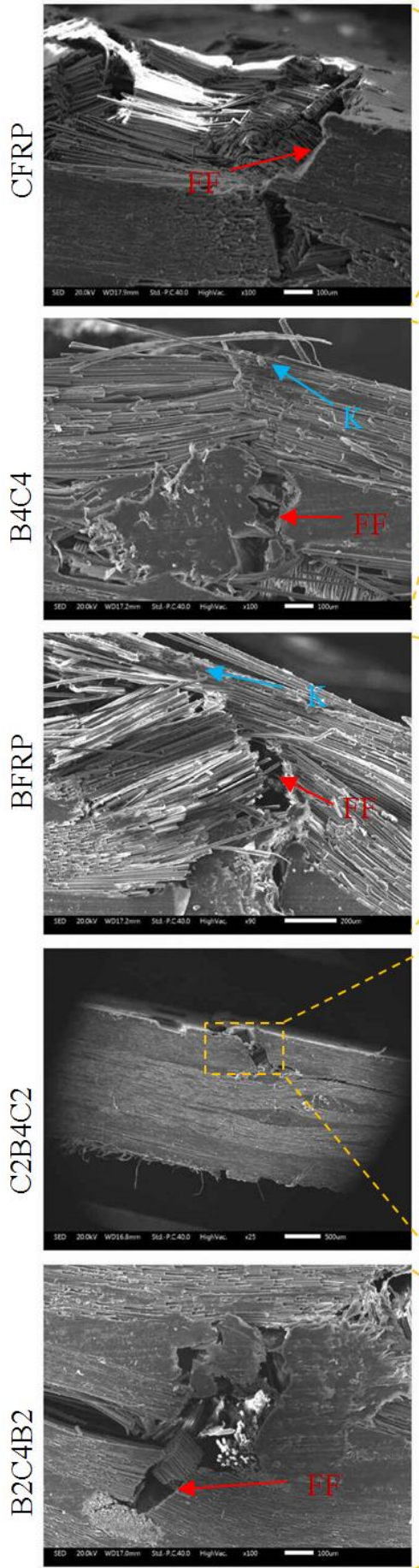

Fiber fracture (FF)
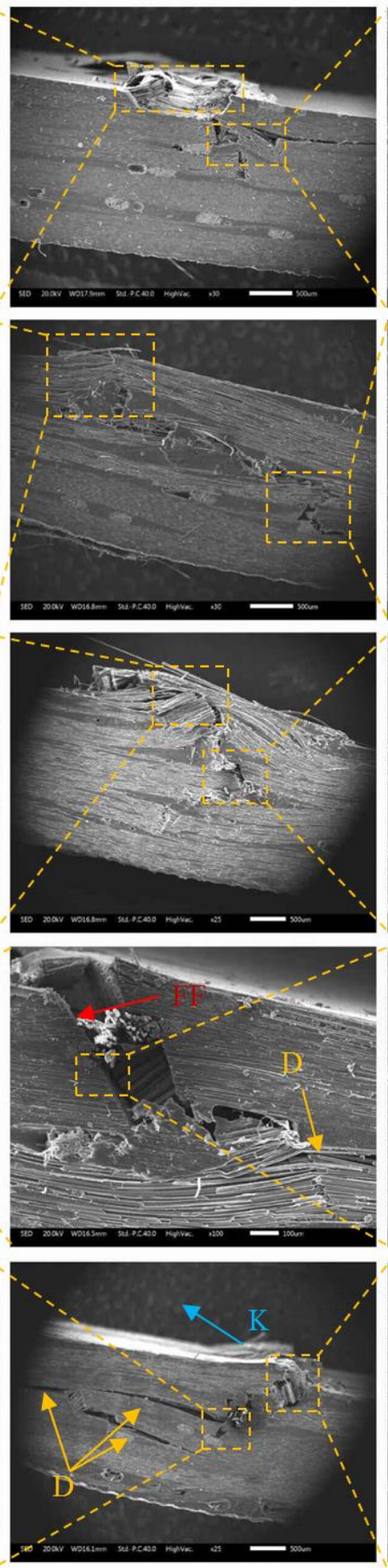

Delamination (D)
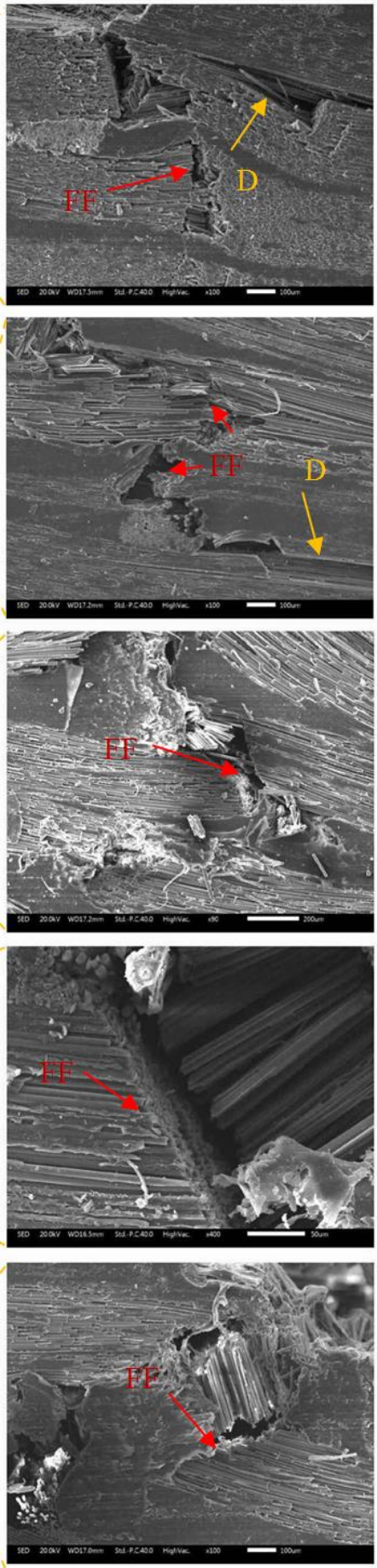

Kinking (K)

Fig. 9. Failure micrograph of hybrid laminates with three magnifications.

As for B4C4, exhibited crack initiated from the compressive side. Micro-buckling and 
shear failure can be also observed among BFRP layers. A closer inspection revealed that delamination existed in the interface of carbon and basalt layers, combining with partial fibre fracture in carbon plies. A lower stress state existed on the compressive side in the B4C4 laminate and thus caused reduction in the flexural modulus and strength by about $18.9 \%$ and $26 \%$ respectively compared to CFRP. Due to the much higher failure strain within the B4C4 laminate, the kink band transferred the flexural load so that a ductile failure mode appeared as shown in Fig.9.

Different failure modes have also been observed from the laminates in the sandwich-like stacking sequences shown in Fig. 9, such as C2B4C2 and B2C4B2. Only compressive failure appeared when the carbon layers were placed on the compressive/tensile sides respectively. It is observed that the shear crack happened at the first two carbon plies together with delamination between the interface of carbon and basalt layers. This phenomenon can be validated by examining the stress distribution across the thickness as shown in Fig. 6(e). Since the damage was only restricted by the carbon layers on the compressive side, only a small reduction in the flexural modulus of the B2C4B2 laminate was observed. When the basalt layers were placed symmetrically on the compressive/tensile sides, respectively, failure appeared mainly on the compressive side, which is similar to $\mathrm{B} 4 \mathrm{C} 4$, but the laminate showed a much better ductile behavior.

\section{Numerical Simulation}

Failure mechanism of fibre-reinforced composite laminates is indeed rather complicated due to their heterogeneous properties that cause various cracking and delamination. Therefore, prediction of these complicated damage modes is of great implication. In this section, the FE model was developed to simulate the damage onset of hybrid carbon/basalt composite laminates, in which the cohesive interface element was employed to characterize the interaction between the neighbouring plies.

\subsection{Finite element modelling}

The FE model of the hybrid carbon/basalt reinforced laminate was developed using ABAQUS/Explicit, a commercial explicit dynamic FE code. The edge effects were neglected in the model, therefore stress distribution along the width was assumed to be uniform. Fig. 10 shows the set-up of the FE model specifically for the B2C4B2 laminate, where the top and bottom layers were the basalt layers. The loading cell and two supports were considered to be the rigid bodies. The continuum shell elements (SC8R) were employed in the FE model.

The mesh density at vicinity of the contact area $(20 \mathrm{~mm} \times 15 \mathrm{~mm})$ was refined. A 
convergence study on discretization was conducted together with test of model parameters, i.e. mesh size and loading rate; and the results are showed in Fig. 11. Mesh subdivision in $z$ direction represents double density of grid across the thickness direction, while mesh size at contact region was refined to be $0.25 \mathrm{~mm}$ (half of non-refined elements) for subdivision in $x y$ plane. Negligible effect appears on force-displacement curves for these two subdivision method from Fig. 11(a). For computing efficiency, mesh density of $0.5 \mathrm{~mm}$ at contact area and one element across each ply were chosen in the present work.

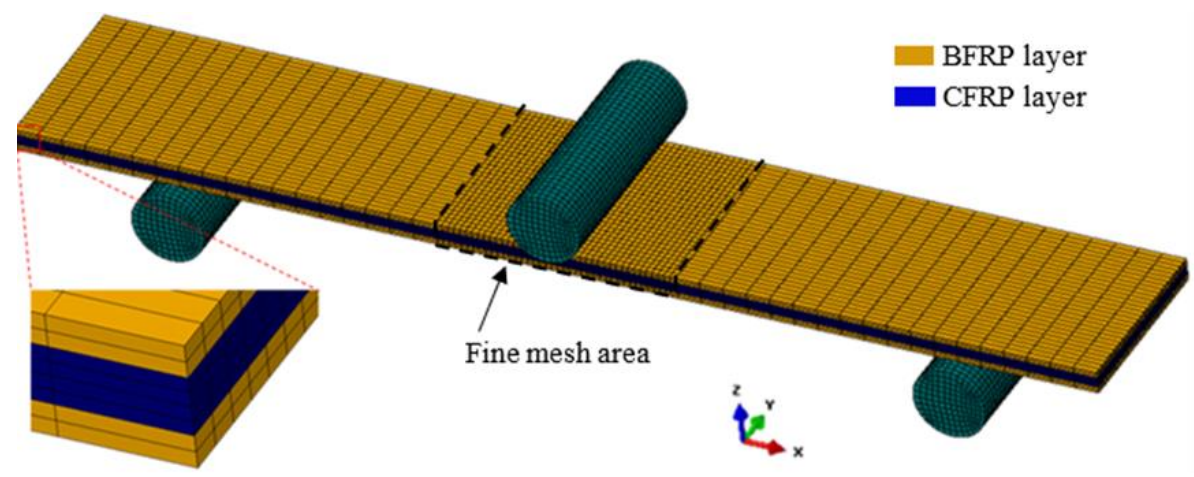

Fig. 10. $\mathrm{FE}$ model for the $\mathrm{B} 2 \mathrm{C} 4 \mathrm{~B} 2$ hybrid composite laminate and configuration of bending simulation.

Cohesive zone method has been commonly used to model adhesives and bonded interfaces [41], in which the zero-thickness cohesive elements were placed onto the adjacent plies to simulate the possible delamination failure in the composite laminates $[24,25]$. The nonlinear constitutive behavior of the cohesive element can be defined by a bilinear traction-separation law [42]. Once a damage initiation criterion is met, linear softening behavior is triggered to simulate the decohesion of the interface elements [41]. The maximum nominal stress criterion was employed to characterize the damage initiation by combining the stress components ratio in the present work. Then, the damage evolution for delamination failure was simulated by the energy law in terms of energy release rate and fracture toughness under mixed-mode loading [24]. The Benzeggagh-Kenane (BK) fracture criterion was used to govern the mixed-mode fracture [41],

$G_{n}^{C}+\left(G_{s}^{C}-G_{n}^{C}\right)\left(\frac{G_{s}+G_{t}}{G_{n}+G_{s}+G_{t}}\right)^{\eta}=G^{C}$

where $G_{n}, G_{s}$ and $G_{t}$ refer to the fracture energies induced by the normal, the first and the second shear forces. $G_{n}^{C}, G_{s}^{C}$ and $G_{t}^{C}$ represent the critical fracture energies required to initiate the crack in the different directions respectively. $\eta$ is the power coefficient. 

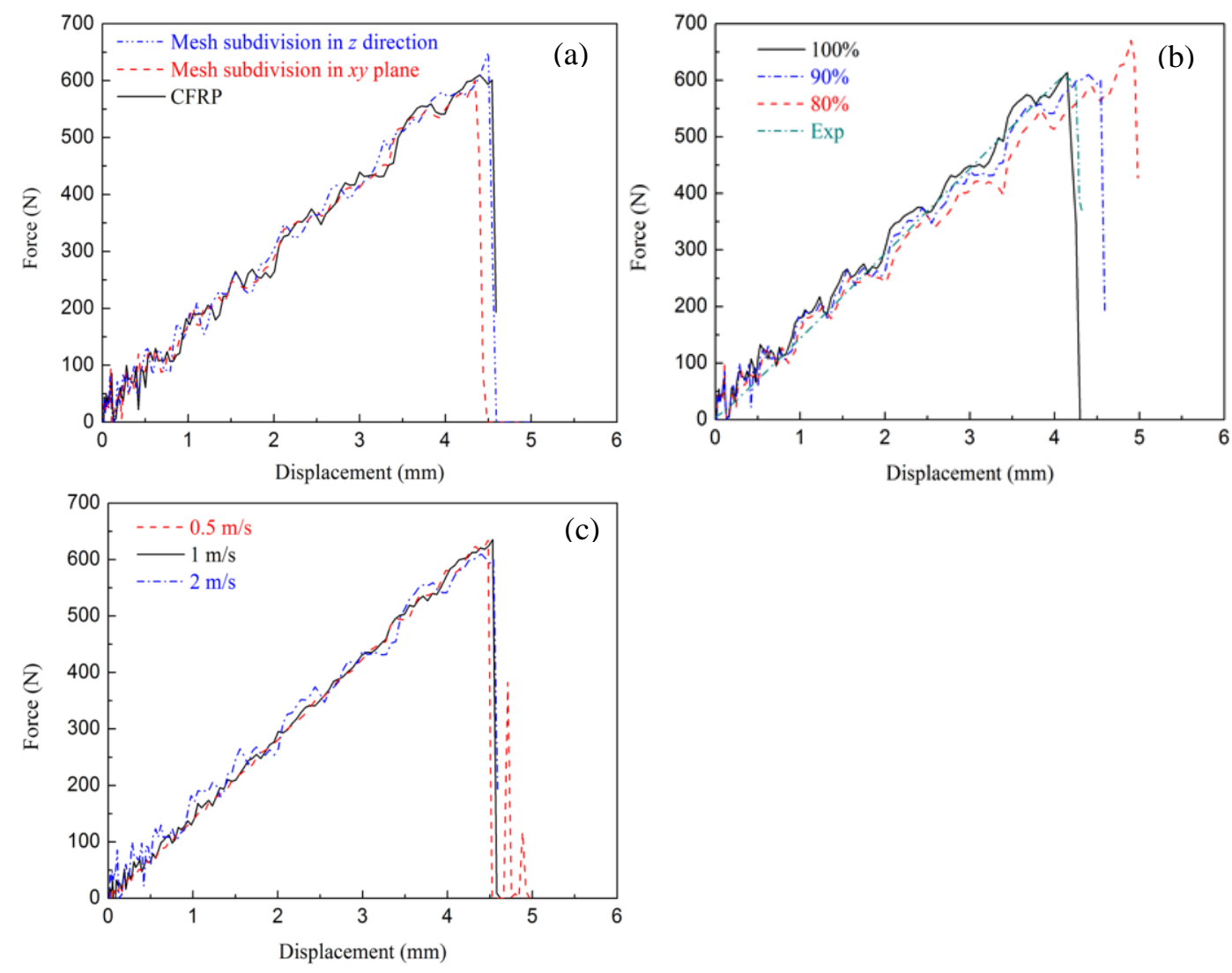

Fig. 11. Convergence study on (a) the CFRP for mesh refinement, (b) ratio of compressive to tensile modulus (c) and loading rate.

It has been shown that the simulation results can be influenced by fluctuation of the damage parameters within around 15\% [43]. These damage parameters include interlaminar normal strength $(30 \mathrm{MPa})$, shear strength $(50 \mathrm{MPa})$, fracture toughness of mode I $(0.26 \mathrm{~N} / \mathrm{mm})$ and mode II $(0.52 \mathrm{~N} / \mathrm{mm})$, respectively [44].

Only the damage initiation of carbon/basalt fibre, rather than damage progress, was modelled here, as the unidirectional composite laminates could fail rapidly once damage initiates. The material properties of the CFRP, BFRP and GFRP laminates have been summarized in Table 1. The compressive strength was taken as $65 \%$ of tensile strength empirically [40]. As in [40], failure in the unidirectional laminate was initiated by the compressive strain in bending due to the relatively lower compressive modulus. Effects of compressive to tensile modulus ratio on the force-displacement were investigated as shown in Fig. 11(b). The fluctuation of numerical curves is due to the progressive contact between the load cell and specimen. It can be observed that the peak bending force increased with the increase in the compressive to tensile modulus ratio. Ratio of compressive to tensile modulus was adopted as $90 \%$ in the present work.

A displacement-controlled load was applied by the load cell while the two supports were 
simply supported. Quasi-static analysis was performed due to its high efficiency for highly nonlinear and large deformation problems. Effect of loading rate was shown in Fig. 11(c); and negligible difference can be seen in terms of force-displacement curves. Thus, an average loading rate of $1 \mathrm{~m} / \mathrm{s}$ was adopted for the following analyses.

\subsection{Validation and analysis}

Typical force-displacement curves of the hybrid composite laminates obtained from the FE simulation and experiment are plotted in Fig. 12 for several representative configurations. A good agreement can be found for those the non-hybrid (CFRP, BFRP and GFRP) laminates, however, the ultimate flexural force of hybrid laminate $\mathrm{C} 2 \mathrm{~B} 4 \mathrm{C} 2$ in the experiment was considerably lower than that of the FE simulation. This is first due to the high sensitivity of carbon fibre on the compressive surface in the three-point bending, which has been systematically discussed in [40]. Second, the C2B4C2 hybrid laminate had a significantly higher ductility when the carbon layers failed on the compressive surface in the experiment, which differ from the FE simulation. It is noted that the stress distribution of composite laminates fluctuated across thickness, particularly near the interface between the carbon and basalt layers as plotted in Fig. 6(e); and it appeared that the hybrid laminates had a higher fluctuation than the non-hybrid counterparts.
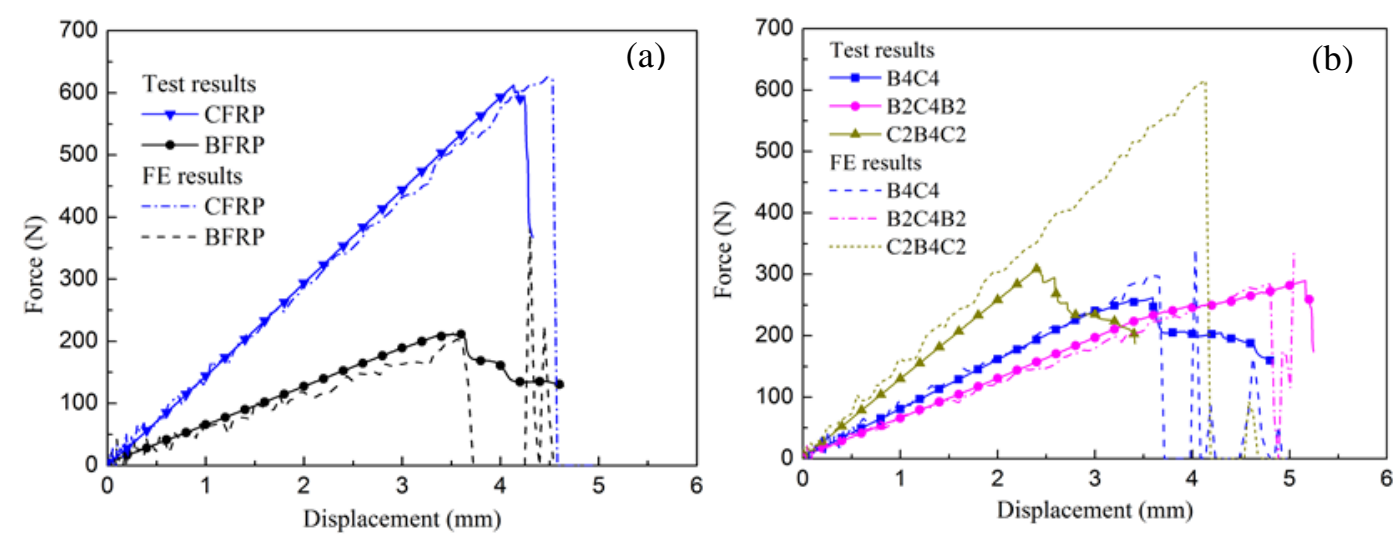

Fig. 12. Comparisons of force-displacement curves between experimental and numerical results.

Fig. 13 illustrates the compressive damage factor of three representative hybrid composite laminates (B4C4, B2C4B2 and $\mathrm{C} 2 \mathrm{~B} 4 \mathrm{C} 2)$ at the moment of damage initiation. For the hybrid laminate with carbon layers on the top, i.e. $\mathrm{C} 2 \mathrm{~B} 4 \mathrm{C} 2$, the compressive damage initiated from the compressive surface underneath the loading cell; and then propagated rapidly across the ply thickness, leading to fracture. When placing ductile layers on the top, i.e. B4C4 and B2C4B2, the damage factor showed a relatively smooth distribution across the ply thickness, the lower plies were still able to carry certain load even though the top ply failed, 
exhibiting better ductility.

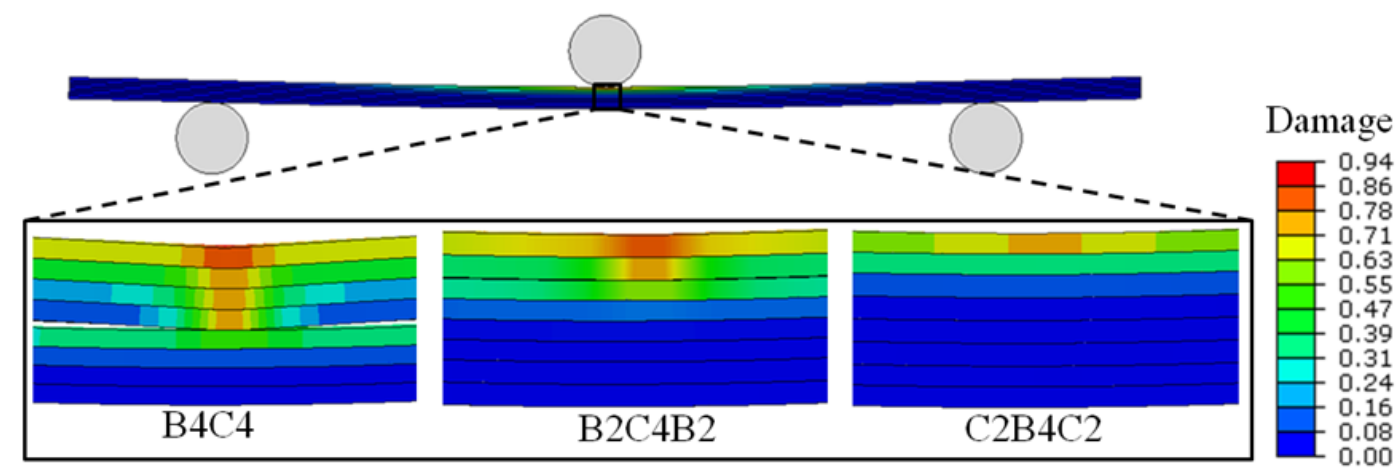

Fig. 13. Damage distribution at the time of failure initiation under three-point bending.

Fig. 14 shows the distribution of flexural stress $\sigma_{11}$ under the transverse load of $150 \mathrm{~N}$. Interestingly the bending stress showed an uneven distribution across the ply thickness, due to the unequal compressive/tensile moduli $\left(\lambda=E_{11}^{c} / E_{11}^{t}=0.9\right)$ and different fibre materials. Apparently, the flexural stress of the top surface is lower than that of the bottom surface. Due to a much lower ratio of compressive to tensile strength $\left(\sigma_{11}^{c} / \sigma_{11}^{t}=0.65\right)$, laminates are vulnerable to fail by a compressive stress. Compared to $\mathrm{C} 2 \mathrm{~B} 4 \mathrm{C} 2$, the other two hybrid laminates appeared a gradual change of flexural compressive stress where damage grew among fibre layers on the compressive side.

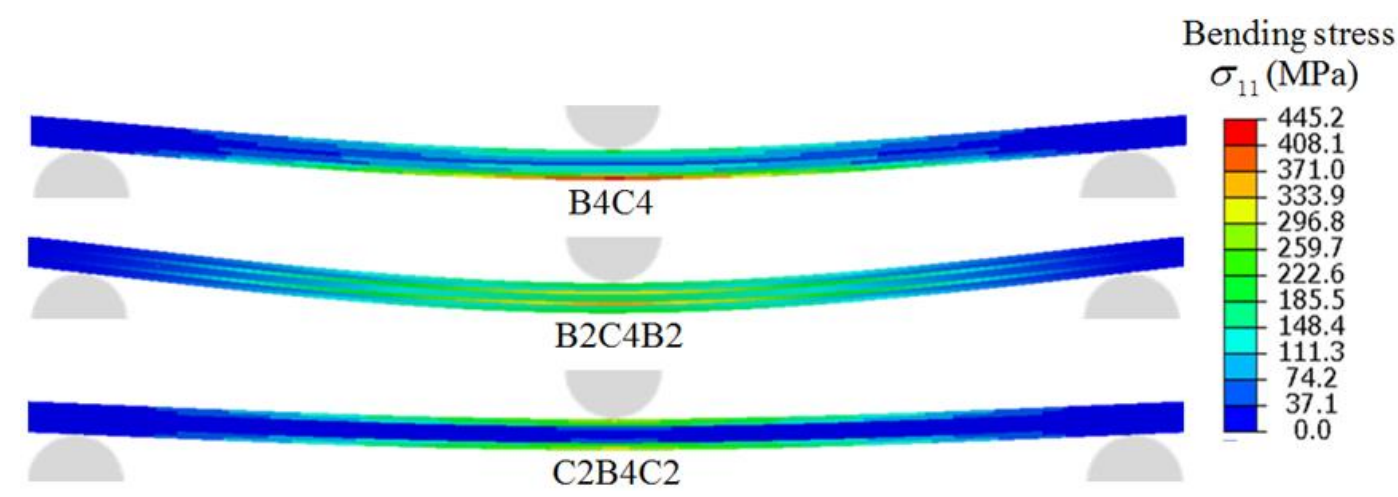

Fig. 14. Contour of bending stress $\sigma_{11}$ under the load of $150 \mathrm{~N}$.

From the above analysis, the stress distribution status was dependent on the stacking sequences of carbon/basalt hybrid laminates, thus resulting in different mechanical responses in bending. It is noted that a smaller reduction on flexural modulus was achieved by placing the carbon fibre layers on the upper and lower laminate surface due to a relatively lower stress near the central plane. So the further investigation was conducted with hybrid C2B4C2 laminate. 


\subsection{Effects of mechanical properties at external sides}

Apart from the $\mathrm{C} 2 \mathrm{~B} 4 \mathrm{C} 2$ laminate that had a large deviation of flexural strength between experiment and FEA, the FEA for other hybrid composite laminates well matched with the experimental results. For this reason, further parametric analysis for $\mathrm{C} 2 \mathrm{~B} 4 \mathrm{C} 2$ was conducted to explore the effects of Young's modulus, lamina strength, and cohesive elements.

Fig. 15 shows the comparison of experiment and FEA for $\mathrm{C} 2 \mathrm{~B} 4 \mathrm{C} 2$, in which different Young's modulus, strength and cohesive properties were tested. It can be seen that there is negligible difference at the peak force (determining the flexural strength), but strain at peak and the slope of curves decreased with decreasing Young's modulus (Fig. 15(a)). As shown in Fig. 15(b), reduction in the strength led to a large variation in the peak flexural force. It is noted that the results on obtained by the FE model with $40 \%$ strength reduction agreed well with the experimental data. Negligible effect can be seen from Fig. 15(c) when changing the cohesive properties (cohesive strength and fracture toughness). In all the three cases as shown in Figs. 15 (a)-(c), the laminate exhibited brittle fracture in the FE simulation, which differs from a progressive failure in the experiment. This is because the FE model has overestimated the compressive strength of carbon layers, and the underneath basalt layers fractured suddenly once the carbon layers failed, showing a catastrophic laminate breakage in bending.
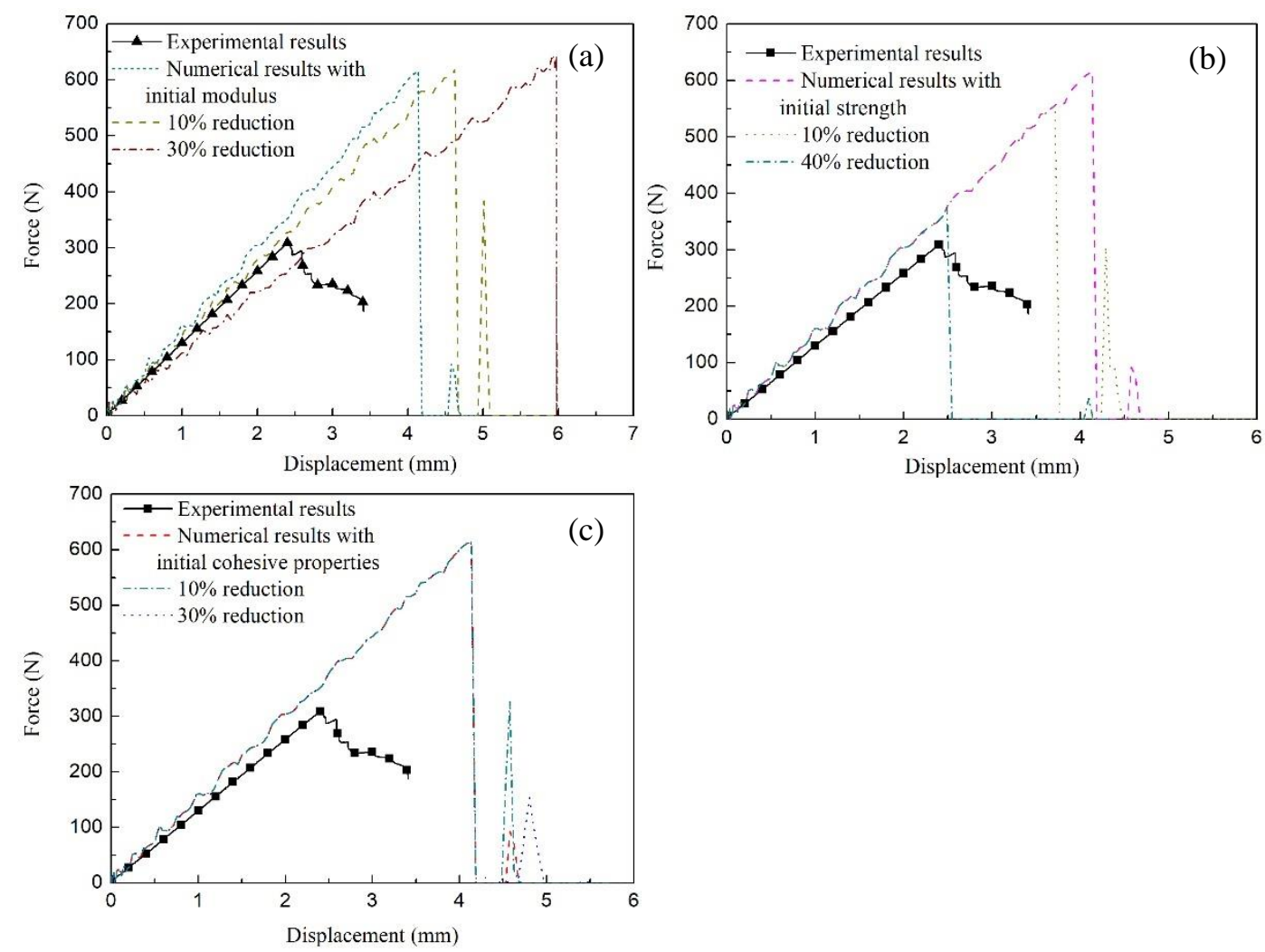

Fig. 15. Comparison of experimental and numerical results with the sensitivity analysis: (a) Young's modulus, (b) tensile strength and (c) cohesive properties. 


\section{Cost analysis}

Table 2 summarizes the material cost for individual hybrid composite laminate, which was normalized to the cost of CFRP laminate. For the non-hybrid laminates, CFRP was the most expensive, about 10.1 and 7.5 times higher than BFRP and GFRP, respectively. This section investigates how to balance the cost and performance of hybrid composite laminate for engineering applications.

The criteria for cost analysis included the ratios of strength/cost and modulus/cost, as plotted in Fig. 16. The bar chart in the figure represents the performance of specific hybrid laminate with the unit cost. While the carbon fibre has much higher performance, glass and basalt fibres did exhibit better cost efficiency (strength/cost and modulus/cost). It is observed that replacing few carbon fibre layers with basalt fibre on the compressive side led to reduction in cost effectiveness (B2C6, B4C4) compared to CFRP laminate according to Fig. 16 , however this trend reversed if more carbon layers were replaced (B6C2).

Table 2 Comparison of material cost. The hybrid laminates have been normalized to CFRP laminate.

\begin{tabular}{ccccc}
\hline Stacking sequence & CFRP cost (\$) & BFRP cost (\$) & GFRP cost (\$) & Total cost (\$) \\
\hline CFRP & $\mathbf{1 0 0 . 0 \%}$ & $0.0 \%$ & $0.0 \%$ & $100.0 \%$ \\
B2C6 & $74.9 \%$ & $2.4 \%$ & $0.0 \%$ & $77.3 \%$ \\
B4C4 & $49.8 \%$ & $4.7 \%$ & $0.0 \%$ & $54.9 \%$ \\
B6C2 & $24.7 \%$ & $7.5 \%$ & $0.0 \%$ & $32.2 \%$ \\
BFRP & $0.0 \%$ & $9.8 \%$ & $0.0 \%$ & $9.8 \%$ \\
B2C4B2 & $49.8 \%$ & $4.7 \%$ & $0.0 \%$ & $54.9 \%$ \\
C2B4C2 & $49.8 \%$ & $4.7 \%$ & $0.0 \%$ & $54.9 \%$ \\
BCBC2BCB & $49.8 \%$ & $4.7 \%$ & $0.0 \%$ & $54.9 \%$ \\
C2G4C2 & $49.8 \%$ & $0.0 \%$ & $6.7 \%$ & $56.5 \%$ \\
G2C4G2 & $49.8 \%$ & $0.0 \%$ & $6.7 \%$ & $56.5 \%$ \\
C2BG2BC2 & $49.8 \%$ & $2.4 \%$ & $3.1 \%$ & $55.7 \%$ \\
BGC4GB & $49.8 \%$ & $2.4 \%$ & $3.1 \%$ & $55.7 \%$ \\
GFRP & $0.0 \%$ & $0.0 \%$ & $13.3 \%$ & $13.3 \%$ \\
\hline
\end{tabular}

Stacking sequence had small effect on the strength/cost but large effect on modulus/cost. With carbon layers at both tensile/compressive surfaces e.g. C2B4C2, C2G4C2 and C2BG2BC2 (hybrid ratio 50\%), there is very good cost efficiency. Of these, C2G4C2 showed the best cost efficiency in terms of modulus/cost and strength/cost ratios due to the high 
elongation and intermediate modulus/strength that basalt fibre provided.

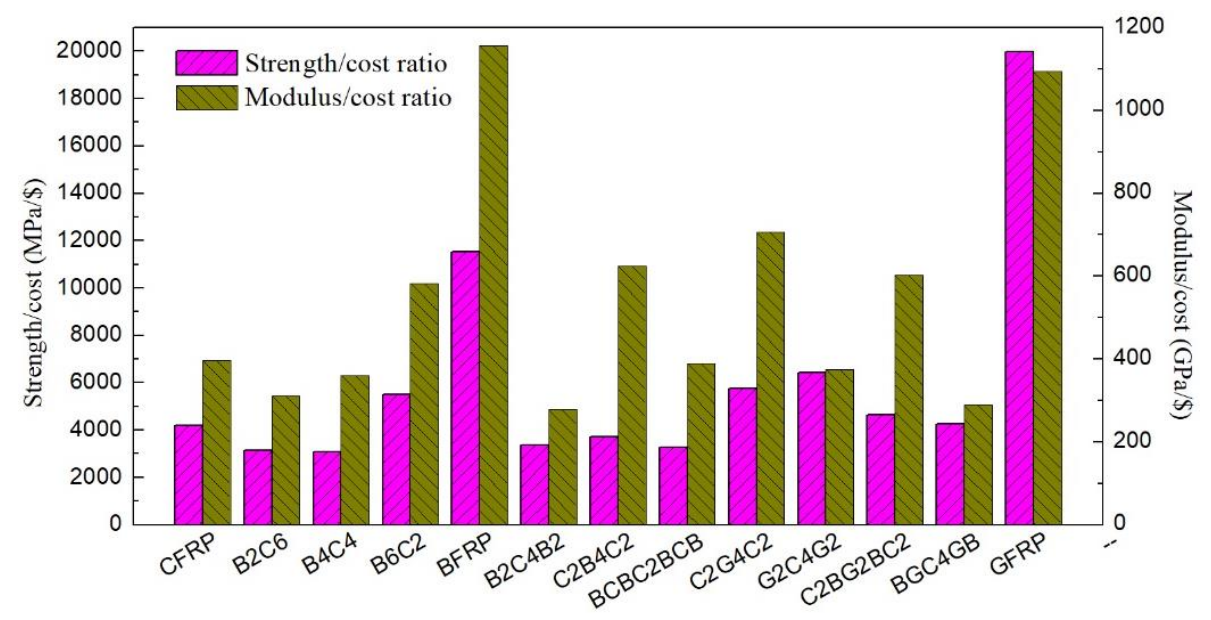

Fig. 16. Comparison of strength/cost and modulus/cost.

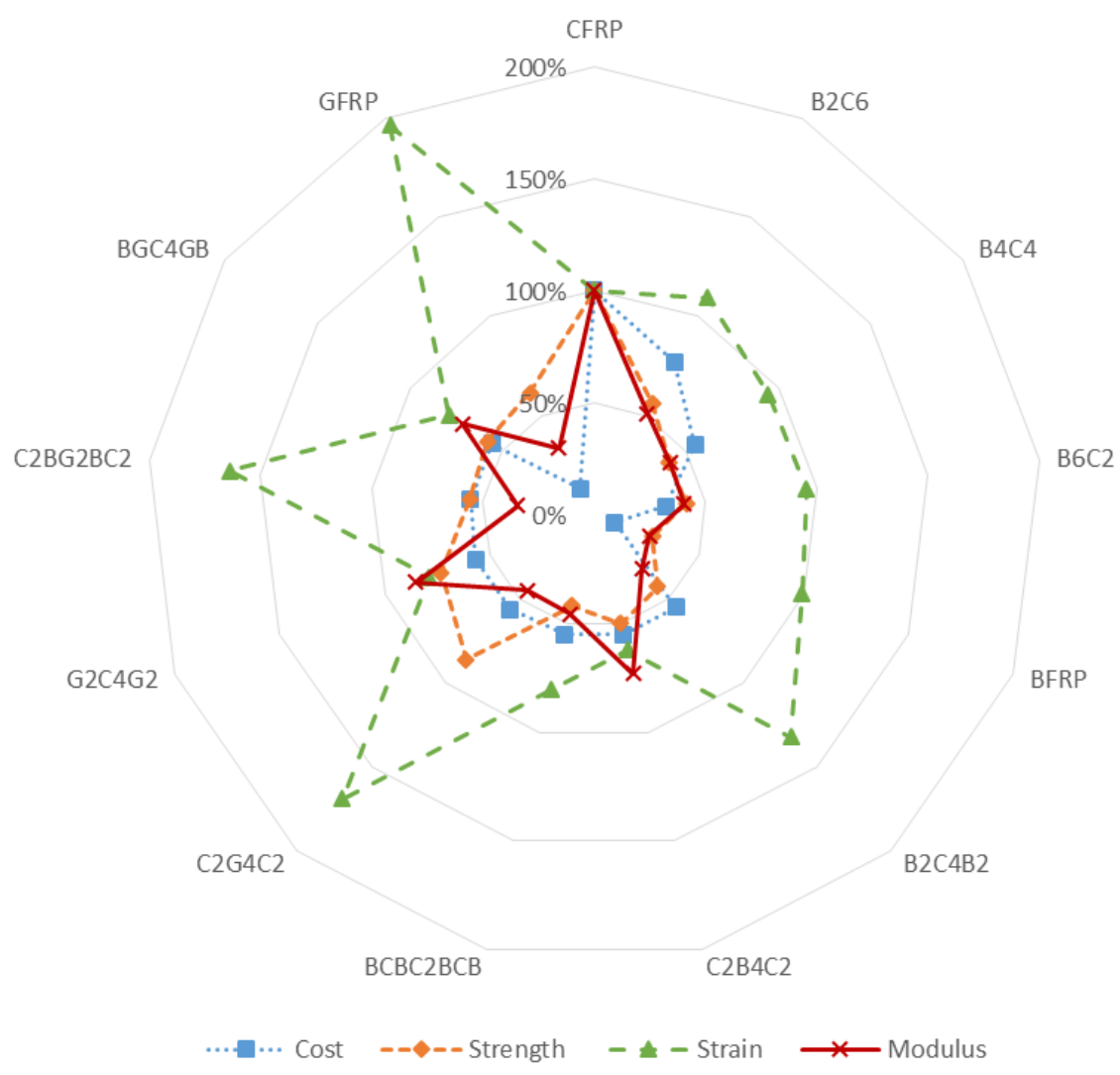

Fig. 17. Performance - cost analysis of hybrid composite laminates. The hybrid laminates have been normalized to CFRP laminate.

In real engineering practice, often designers need to ensure the specific structural performance before considering cost reduction. It would be more effective to combine the performance and cost together at the design stage. Fig. 17 shows a radar chart for the hybrid composite laminates by considering the cost, flexural strength, modulus and ductility (strain). As shown in Fig. 16, pure BFRP composite showed much higher cost efficiency than CFRP, 
however it is unlikely to employ this material in high-end large structural components such as wind turbine blade and aircraft fuselage owing to its lower mechanical properties. On the other hand, for some intermediate structural components, such as civilian vehicle body which requires high cost efficiency and material ductility but less sensitivity of modulus, the hybrid laminates $\mathrm{C} 2 \mathrm{BG} 2 \mathrm{BC} 2$ and $\mathrm{C} 2 \mathrm{G} 4 \mathrm{C} 2$ can be potential candidates.

\section{Conclusion}

A systematic study has been carried out to investigate the flexural performance of hybrid carbon/glass/basal fibres by using experimental, analytical and numerical approaches. With significant difference of material properties among the three fibres, the flexural performance of hybrid laminates (flexural modulus, flexural strength and ductility) compromised with different hybrid ratios and stacking sequences. With increase in the hybrid ratio, flexural modulus and flexural strength decreased while ductility increased. In general, the glass fibre presented better performance than basalt fibre in the hybrid composite laminates.

The surface plies carried more load under bending, thus dominated the failure modes of the hybrid composite laminates. All the laminates failed by compression in three-point bending tests regardless of hybrid ratio and stacking sequence, which has not been reported in the previous literature. Through a FEA parametric study this was confirmed to be a result of the unequal compressive/tensile moduli and strengths. Further, the stacking sequence played an important role on the progressive failure of laminates after the damage initiation, meaning that investigation into the damage evolution can help to understand the mechanical behavior of the hybrid composites. C2GB2GC2 and C2G4C2 hybrid laminates, for instance, have a small reduction of load carrying capacity but a massive improvement of ductility and cost efficiency, making them a potential candidate for many structural components subject to bending, such as vehicle chassis.

Note that the material cost of these three fibres are nonlinear to their respective mechanical performance, therefore the cost analysis can provide better understanding to balance the performance and cost. This is particularly important to the applications with less sensitivity of strength to weight, such as marine structures. The present study suggested a radar chart approach by considering four factors (cost, strength, modulus and strain) to analyze the performance to cost efficiency of the hybrid composites. As the 3D CLT analysis and FEA model have been validated by the experimental results, future studies can be carried out by using these two 'low cost' approaches to complement the radar chart. 


\section{Acknowledge}

This work is supported by National Natural Science Foundation of China (51575172, 51475154). Dr Guangyong Sun is a recipient of Australian Research Council (ARC) Discovery Early Career Researcher Award (DECRA) in the University of Sydney.

\section{References}

1. Zhu, G., et al., Energy absorption of metal, composite and metal/composite hybrid structures under oblique crushing loading. International Journal of Mechanical Sciences, 2018. 135: p. 458-483.

2. Sun, G., et al., On crashing behaviors of aluminium/CFRP tubes subjected to axial and oblique loading: An experimental study. Composites Part B: Engineering, 2018. 145: p. 47-56.

3. Zhu, G., et al., Modeling for CFRP structures subjected to quasi-static crushing. Composite Structures, 2018. 184: p. 41-55.

4. Huda, Z. and P. Edi, Materials selection in design of structures and engines of supersonic aircrafts: A review. Materials \& Design, 2013. 46: p. 552-560.

5. Paiva, J.M.F.d., A.D.N.d. Santos, and M.C. Rezende, Mechanical and morphological characterizations of carbon fiber fabric reinforced epoxy composites used in aeronautical field. Materials Research, 2009. 12(3): p. 367-374.

6. Zhang, K., et al., Mechanical characterization of hybrid lattice-to-steel joint with pyramidal CFRP truss for marine application. Composite Structures, 2017. 160: p. 1198-1204.

7. Leone, C., et al., Investigation of CFRP laser milling using a $30 \mathrm{~W} Q$-switched $Y b: Y A G$ fiber laser: Effect of process parameters on removal mechanisms and HAZ formation. Composites Part A: Applied Science and Manufacturing, 2013. 55: p. 129-142.

8. $\mathrm{Xu}, \mathrm{J} ., \mathrm{Q}$. An, and M. Chen, A comparative evaluation of polycrystalline diamond drills in drilling high-strength T800S/250F CFRP. Composite Structures, 2014. 117: p. 71-82.

9. Ary Subagia, I.D.G., et al., Effect of stacking sequence on the flexural properties of hybrid composites reinforced with carbon and basalt fibers. Composites Part B: Engineering, 2014. 58: p. 251-258.

10. Prusty, R.K., et al., Experimental optimization of flexural behaviour through inter-ply fibre hybridization in FRP composite. Construction and Building Materials, 2016. 118: p. 327-336.

11. Swolfs, Y., L. Gorbatikh, and I. Verpoest, Fibre hybridisation in polymer composites: A review. Composites Part A: Applied Science and Manufacturing, 2014. 67: p. 181-200.

12. Yang, Z., et al., Effect of matrix glass transition on reinforcement efficiency of epoxy-matrix composites with single walled carbon nanotubes, multi-walled carbon nanotubes, carbon nanofibers and graphite. Composites Part B: Engineering, 2012. 43(4): p. 2079-2086.

13. Shin, M.K., et al., Synergistic toughening of composite fibres by self-alignment of reduced graphene oxide and carbon nanotubes. Nat Commun, 2012. 3: p. 650.

14. Taniguchi, N., et al., Dynamic tensile properties of carbon fiber composite based on thermoplastic epoxy resin loaded in matrix-dominant directions. Composites Science and Technology, 2009. 69(2): p. 207-213.

15. Hufenbach, W., et al., Determination of strain rate dependent through-thickness tensile properties of textile reinforced thermoplastic composites using L-shaped beam specimens. Composites 
Science and Technology, 2011. 71(8): p. 1110-1116.

16. Sonnenfeld, C., et al., Thermoplastic/thermoset multilayer composites: A way to improve the impact damage tolerance of thermosetting resin matrix composites. Composite Structures, 2017. 171: p. 298-305.

17. Zhang, J., et al., Hybrid composite laminates reinforced with glass/carbon woven fabrics for lightweight load bearing structures. Materials \& Design (1980-2015), 2012. 36: p. 75-80.

18. Wu, Z., et al., Electrical and mechanical characterization of hybrid CFRP sheets. Journal of composite materials, 2006. 40(3): p. 227-244.

19. Czél, G. and M.R. Wisnom, Demonstration of pseudo-ductility in high performance glass/epoxy composites by hybridisation with thin-ply carbon prepreg. Composites Part A: Applied Science and Manufacturing, 2013. 52: p. 23-30.

20. Dong, C. and I.J. Davies, Flexural strength of bidirectional hybrid epoxy composites reinforced by E glass and T700S carbon fibres. Composites Part B: Engineering, 2015. 72: p. 65-71.

21. Kalantari, M., C. Dong, and I.J. Davies, Multi-objective analysis for optimal and robust design of unidirectional glass/carbon fibre reinforced hybrid epoxy composites under flexural loading. Composites Part B: Engineering, 2016. 84: p. 130-139.

22. Pandya, K.S., C. Veerraju, and N.K. Naik, Hybrid composites made of carbon and glass woven fabrics under quasi-static loading. Materials \& Design, 2011. 32(7): p. 4094-4099.

23. Meng, M., et al., 3D FEA modelling of laminated composites in bending and their failure mechanisms. Composite Structures, 2015. 119: p. 693-708.

24. Ullah, H., et al., Finite-element modelling of bending of CFRP laminates: Multiple delaminations. Computational Materials Science, 2012. 52(1): p. 147-156.

25. Ullah, H., A.R. Harland, and V.V. Silberschmidt, Experimental and Numerical Analysis of Damage in Woven GFRP Composites Under Large-deflection Bending. Applied Composite Materials, 2012. 19(5): p. 769-783.

26. Jalalvand, M., G. Czél, and M.R. Wisnom, Numerical modelling of the damage modes in UD thin carbon/glass hybrid laminates. Composites Science and Technology, 2014. 94: p. 39-47.

27. Jalalvand, M., M. Fotouhi, and M.R. Wisnom, Orientation-dispersed pseudo-ductile hybrid composite laminates - A new lay-up concept to avoid free-edge delamination. Composites Science and Technology, 2017. 153: p. 232-240.

28. Dong, C., H.A. Ranaweera-Jayawardena, and I.J. Davies, Flexural properties of hybrid composites reinforced by S-2 glass and T700S carbon fibres. Composites Part B: Engineering, 2012. 43(2): p. 573-581.

29. Kalantari, M., C. Dong, and I.J. Davies, Numerical investigation of the hybridisation mechanism in fibre reinforced hybrid composites subjected to flexural load. Composites Part B: Engineering, 2016. 102: p. 100-111.

30. Dhand, V., et al., A short review on basalt fiber reinforced polymer composites. Composites Part B: Engineering, 2015. 73: p. 166-180.

31. Fiore, V., et al., A review on basalt fibre and its composites. Composites Part B: Engineering, 2015. 74: p. 74-94.

32. Dorigato, A. and A. Pegoretti, Flexural and impact behaviour of carbon/basalt fibers hybrid laminates. Journal of Composite Materials, 2013. 48(9): p. 1121-1130.

33. Nisini, E., C. Santulli, and A. Liverani, Mechanical and impact characterization of hybrid composite laminates with carbon, basalt and flax fibres. Composites Part B: Engineering, 2017. 
127: p. 92-99.

34. Najafi, M., S.M.R. Khalili, and R. Eslami-Farsani, Hybridization effect of basalt and carbon fibers on impact and flexural properties of phenolic composites. Iranian Polymer Journal, 2014. 23(10): p. 767-773.

35. $\mathrm{Wu}, \mathrm{Z}$., et al., Tensile fatigue behaviour of FRP and hybrid FRP sheets. Composites Part B: Engineering, 2010. 41(5): p. 396-402.

36. Astm, D.D., Standard Test Method for Flexural Properties of Polymer Matrix Composite Materials. Astm, 2010.

37. Kaw, A.K., Mechanics of composite materials. 2005: CRC press.

38. Standard, A., Standard test method for tensile properties of polymer matrix composite materials. ASTM D3039/D M, 2008. 3039: p. 2008.

39. Standard, A., Standard Test Method For In-Plane Shear Response of Polymer Matrix Composite Materials by Tensile Test of a 45 Laminate. ASTM D 3518/D 3518, 2001.94.

40. Meng, M., et al., The effects of unequal compressive/tensile moduli of composites. Composite Structures, 2015. 126: p. 207-215.

41. Version, A., 6.13, Analysis User's Manual. Dassault Systemes Simulia Corp., Providence, RI, 2013.

42. Tan, W., et al., Predicting low velocity impact damage and Compression-After-Impact (CAI) behaviour of composite laminates. Composites Part A: Applied Science and Manufacturing, 2015. 71: p. 212-226.

43. Sokolinsky, V.S., K.C. Indermuehle, and J.A. Hurtado, Numerical simulation of the crushing process of a corrugated composite plate. Composites Part A: Applied Science and Manufacturing, 2011. 42(9): p. 1119-1126.

44. Shin, D.K., H.C. Kim, and J.J. Lee, Numerical analysis of the damage behavior of an aluminum/CFRP hybrid beam under three point bending. Composites Part B: Engineering, 2014. 56: p. 397-407. 